$\overline{\text { ARTí́CULOS }}$ 



\title{
LAS REVISTAS ACADÉMICAS ESPAÑOLAS DE ESTUDIOS FÍLMICOS. UNA CARTOGRAFÍA ${ }^{1}$
}

Spanish Film Studies Journals. A Cartography

\author{
Jorge Nieto FERrANDO a
}

Universitat de Lleida

Asier ARANZubia ${ }^{\mathrm{b}}$

Universidad Carlos III de Madrid

DOI: $10.15366 /$ secuencias2020.51.001

\section{RESUMEN}

Este artículo ofrece un inventario de las principales revistas académicas sobre cine que se han editado en España a lo largo de los últimos cuarenta años. Durante la década de los setenta del siglo pasado se pueden encontrar revistas de carácter híbrido en las que la atención a la actualidad convive ya con los primeros balbuceos de un discurso científico en torno al cine. La consolidación de los estudios universitarios de comunicación en la década de los ochenta propiciará la creación de las primeras revistas científicas dedicadas exclusivamente al cine. A las pioneras de los ochenta, Cinematògraf, Archivos de la Filmoteca e Ikusgaiak se sumarán, ya en la década siguiente, publicaciones como Filmhistoria, Cinema Rescat o Secuencias. Revista de historia del cine. Con la llegada del siglo XXI, las revistas académicas pasarán a desempeñar una función esencial dentro del nuevo sistema de acreditación del profesorado universitario. Las numerosas dificultades que las revistas de cine han encontrado para adaptarse a este nuevo escenario, unidas a la precaria situación de la investigación en el campo de los estudios fílmicos, han sumido al sector en una profunda crisis.

Palabras clave: Contracampo, Cinematògraf, Archivos de la Filmoteca, Ikusgaiak, Filmhistoria, Cinema Rescat, Secuencias. Revista de historia del cine, Cuadernos de la Academia, L'Atalante, Eutopías.

\section{ABSTRACT}

This article offers an inventory of the main Film Studies journals that have been published in Spain over the past forty years. During the seventies, it was possible to find hybrid magazines where the attention to current affairs coexisted with what can be considered the first attempts of writing a scientific discourse on cinema. The consolidation of Media and Communication Studies at university level in the 1980 os promoted the creation of the first scientific magazines devoted exclusively to cinema. To the pioneers of the eighties, Cinematograf, Archivos de la Filmoteca and Ikusgaiak, were added in the following decade publications such as Filmhistoria, Cinema Rescat and Secuencias. Revista de historia del cine. With the arrival of the 21st Century, academic journals started to play an essential role within the new university faculty accreditation system. The numerous difficulties that film magazines have found in adapting to this new scenario, together with the precarious situation of research in the field of Film Studies, have plunged the sector into a deep crisis.

Keywords: Contracampo, Cinematògraf, Archivos de la Filmoteca, Ikusgaiak, Filmhistoria, Cinema Rescat, Secuencias. Revista de historia del cine, Cuadernos de la Academia, L'Atalante, Eutopías.

[1] [Nota de los autores] Este artículo está dedicado a la memoria de uno de los pioneros en el campo de las revistas académicas de cine: Alberto Elena. La feliz coincidencia de que vea la luz, precisamente, en la que fue «la casa del Amigo» nos llena de satisfacción. [Nota de los editores] Agradecemos a Jorge Nieto y Asier Aranzubia la aceptación de nuestra invitación para la escritura de este texto con motivo de la conmemoración del vigésimo quinto aniversario de la aparición del primer número de Secuencias. Revista de historia del cine. [a] Jorge Nieto Ferrando es profesor de la Universitat de Lleida y responsable del «Grupo de investigación en las transformaciones de los medios audiovisuales y sus implicaciones en el desarrollo político, cultural y social», de la misma universidad. Ha publicado en revistas como Archivos de la Filmoteca, Secuencias. Revista de historia del cine, Comunicación y Sociedad, Historia y Comunicación Social, Signa, L'Atalante, Revista Latina de Comunicación Social, ZER o Estudios sobre el Mensaje Periodístico. Es autor, entre otros libros, de Posibilismos, memorias y fraudes. El cine de Basilio Martín Patino (2006), Cine en papel. Cultura y crítica cinematográfica en España (1939-1962) (2009), Cine en papel. Cultura y crítica cinematográfica en España (19621982) (2013), La oposición al franquismo en el cine (2018) o, junto a José Enrique Monterde, de La prensa cinematográfica en España, 1910-2010 (2018), premio Ricardo Muñoz Suay de la Academia de las Artes y las Ciencias Cinematográficas de España. También ha co-coordinado los libros Por un cine de lo real. Cincuenta años después de las Conversaciones de Salamanca (2006) (premio al mejor trabajo colectivo de investigación de la Asociación Española de Historiadores del Cine) o, entre otros, Diccionario del audiovisual valenciano (2018). E-mail: jorge.nieto@udl.cat

[b] Asier Aranzubia es profesor en el Departamento de Comunicación de la Universidad Carlos III de Madrid y miembro del grupo de investigación Diversidad Audiovisual. Ha participado en numerosos libros colectivos y en diversas publicaciones académicas, entre ellas, Secuencias. Revista de historia del cine, Archivos de la Filmoteca, Revista de Occidente, ZER, Signa, L'Atalante o Studies in Spanish \& Latin American Cinemas. Entre 2007 y 2011 formó parte del consejo de redacción de Cahiers du Cinéma España donde también colaboró como crítico. Entre 2012 y 2017 fue miembro del consejo de redacción de Caimán. Cuadernos de cine. Es autor de Carlos Serrano de Osma. Historia de una obsesión (Filmoteca Española, 2007), premio al mejor trabajo monográfico de investigación de la Asociación Española de Historiadores del Cine; de la monografía Alexander Mackendrick (Cátedra, 2011) y de los libros de entrevistas El mapa de la India. Conversaciones con Manolo Matji (Cuadernos Tecmerin, 2013) y Bulevar de los recuerdos. Una conversación con Manuel Vidal Estévez (Materiales por derribo, 2020). Recientemente ha coordinado dos antologías para la editorial Shangrila: Los mecanismos comunicativos del cine de todos los días. Antología del colectivo Marta Hernández y Javier Maqua en Comunicación XXI (2016) y Carlos Serrano de Osma. Sombras iluminadas (2019). E-mail: aaranzub@hum.uc3m.es 


\section{Introducción}

La progresiva consolidación de los estudios universitarios de comunicación en la década de los ochenta propiciará la aparición de las primeras revistas académicas que acogen en sus páginas investigaciones relacionadas con el cine. Aunque ya en la década anterior (e incluso antes) se habían publicado artículos en las revistas especializadas que hacían, aunque fuera de manera tentativa, uso de herramientas metodológicas propias de un discurso científico, habrá que esperar, como decimos, a la consolidación de una comunidad científica en los ochenta para poder hablar con propiedad de revistas y artículos académicos.

Antes de seguir adelante con esta aproximación a la evolución de las revistas académicas españolas del campo de los estudios fílmicos urgen una serie de precisiones conceptuales que nos sirvan para aclarar de qué hablamos exactamente cuando hablamos de revistas académicas. En primer lugar, es preciso señalar que la razón de ser de estas revistas no es otra que dar salida a la producción científica de los investigadores universitarios. Las revistas académicas son, por lo tanto, las plataformas por medio de las cuales los investigadores comparten con sus pares los resultados de sus investigaciones. Es por eso que la consolidación de los estudios de comunicación entre nosotros era un requisito previo para que nacieran estas publicaciones. Y es por eso también que la naturaleza de los artículos que se publican en estas revistas es muy distinta a la de los textos que se difunden a través de las llamadas revistas especializadas. Como bien ha explicado Imanol Zumalde ${ }^{2}$, las revistas académicas no están sujetas, como sucede con las especializadas, a los siempre acelerados ritmos de la actualidad. El suyo es un discurso condicionado por debates teóricos y metodológicos de largo recorrido - que se vienen desarrollando, desde antiguo, en el seno de la universidad-y no por las urgencias de una actualidad cinematográfica que exige casi siempre una respuesta en caliente, es decir, inmediata. Otra de las diferencias estriba en que las revistas especializadas se dirigen a un público generalista mientras que el destinatario ideal de las académicas es un público especializado: en esencia, la comunidad científica. La mera extensión de los artículos, la mayor complejidad discursiva, el empleo de un determinado instrumental conceptual y de una metodología concreta son algunos de los rasgos distintivos de los textos académicos y vienen, como estamos intentando demostrar, en buena medida condicionados por los objetivos que persiguen estas publicaciones y por el perfil (muy especializado) de su público ideal (la comunidad científica).

El presente artículo ofrece un inventario de las revistas académicas españolas que han acogido investigaciones de corte histórico, teórico o analítico en torno al cine a lo largo de los últimos cuarenta años. La cartografía de revistas que ofrecemos aquí no es definitiva - en la medida en que no se han consignado todas- pero sí es lo suficientemente representativa como para que el lector se haga una idea aproximada de cómo ha evolucionado a lo largo de las últimas décadas el ámbito específico de las revistas científicas de cine. A modo de con-

[2] Imanol Zumalde, La experiencia fílmica. Cine, pensamiento y emoción (Madrid, Cátedra, 2011), pp. 15-27. 
[3] Jorge Nieto Ferrando, Cine en papel. Cultura y crítica cinematográfica en España (19621982) (Valencia, Ediciones de la Filmoteca, 2012), p. 66.

[4] Asier Aranzubia, «Entrevista telefónica del autor a Pablo del Río» (Madrid, 19 de mayo de 2015).

[5] Citado por Jorge Nieto Ferrando en Cine en papel, p. 66.

[6] Véase Asier Aranzubia «Vida y milagros de una revista de combate. Contracampo (1979-1987)», en Jenaro Talens y Santos Zunzunegui (eds.). Contracampo. Ensayos sobre teoría e historia del cine (Madrid, Cátedra, 2007), pp. 13-34; Asier Aranzubia y Jorge Nieto Ferrando, «Un idilio efímero o de cómo el influjo de la teoría renovó la crítica cinematográfica española en los años 70» (Secuencias. Revista de historia del cine, n. $\left.{ }^{0} 37,2013\right)$, pp. $62-$ 82; y Alejandro Montiel, «Días inolvidables. La recepción del cine español de la transición en los editoriales de contracampo», en Arturo Lozano Aguilar y Julio Pérez Perucha (eds.), «El cine español durante la transición democrática (1974-1983)» (Cuadernos de la Academia, n. ${ }^{\circ} 13-14$, 2005), pp. 257-274. clusión, se ha incluido un epígrafe en el que se reflexiona sobre los problemas a los que se enfrenta actualmente la difusión de la investigación en el ámbito de los estudios fílmicos.

\section{Antecedentes y primeras tentativas}

Hubo un tiempo en el que los límites entre lo que era una publicación académica y una especializada no estaban tan claros como lo están actualmente. Hasta el punto de que bien podríamos hablar de revistas híbridas, esto es, publicaciones en las que el repaso a la actualidad cinematográfica sigue ocupando un lugar preferente, pero en las que afloran ya los primeros balbuceos de un discurso científico en torno al cine. Tal vez, la publicación periódica española en la que conviven de una manera más evidente ambos discursos sea Comunicación XXI. Nacida en 1972 tras la reconversión de Estafeta de la publicidad en una revista que pretendía dar respuestas comunes a los problemas que se plantean en los distintos ámbitos de la comunicación - periodismo, publicidad, diseño, televisión, cine, etc.-, Comunicación XXI dio sus primeros pasos «en un contexto de marcado interés editorial por todo lo relacionado con la comunicación social y, en especial, con la publicidad» ${ }^{3}$. Según Pablo del Río ${ }^{4}$, Redactor Jefe de la publicación en su primera etapa, la revista se había autoimpuesto el ambicioso objetivo de «estructurar teóricamente el mundo de la comunicación» para otorgarle así la entidad científica de la que entonces carecía. Con un diseño muy atractivo y una tirada modesta - entre dos mil y tres mil ejemplares- que les permitía un mayor margen de maniobra de cara a la censura - a menor difusión, mayor permisibilidad-, a la revista le cupo el honor de entrevistar a figuras internacionales de la comunicación como Abraham Moles y Marsall McLuhan y contó entre sus redactores con nombres que después harían aportaciones importantes al ámbito de la investigación en comunicación: Manuel Vázquez Montalbán - quién publicará en la revista la serie «Lecciones de historia de la comunicación» que después daría lugar a su célebre Historia y comunicación social ${ }^{5}$-, Román Gubern, Miquel de Moragas, Domènec Font, Santos Zunzunegui, etc.

No por casualidad, de la sección de cine de la revista se encargará el Nuevo Frente Crítico (NFC) o, lo que es lo mismo, esa nueva generación de críticos que desde finales de los sesenta está intentando renovar el anquilosado discurso de la crítica española a través de la incorporación de toda una serie de herramientas teóricas y metodológicas procedentes, en su mayor parte, de la órbita del estructuralismo. La sección de cine de Comunicación XXI supone la primera tentativa de análisis de las películas de la cartelera desde una perspectiva científica. A partir de aquí, el proyecto de renovación del discurso crítico que impulsa el NFC se desarrollará al abrigo de tres revistas especializadas -Fỉm guía, La Mirada y Contracampo- que, aunque siguen prestando una atención preferente a la actualidad y están dirigidas a un público cinéfilo, anticipan ya, en cierta medida, la irrupción, en la década siguiente, de las revistas académicas ${ }^{6}$. Donde se va a 
ver más clara esa condición híbrida del discurso del NFC es durante la segunda etapa de Contracampo y en la primera época de Archivos de la Filmoteca.

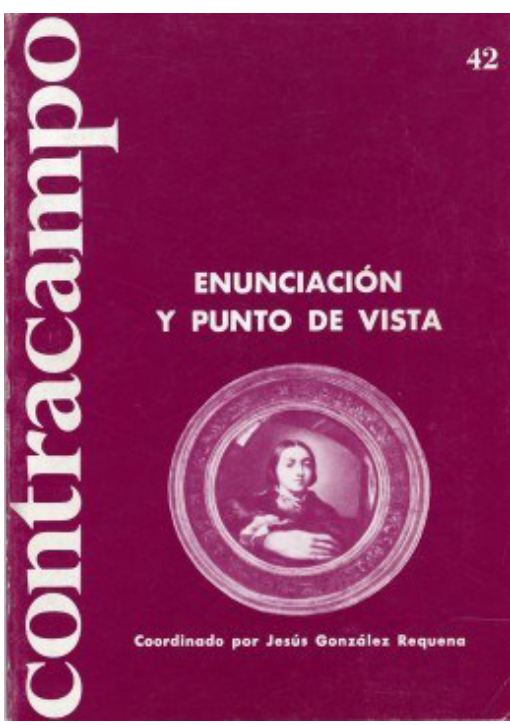

Jesús González Requena (coord.), «Enunciación y punto de vista». Contracampo, n. ${ }^{\circ} 42,1987$.

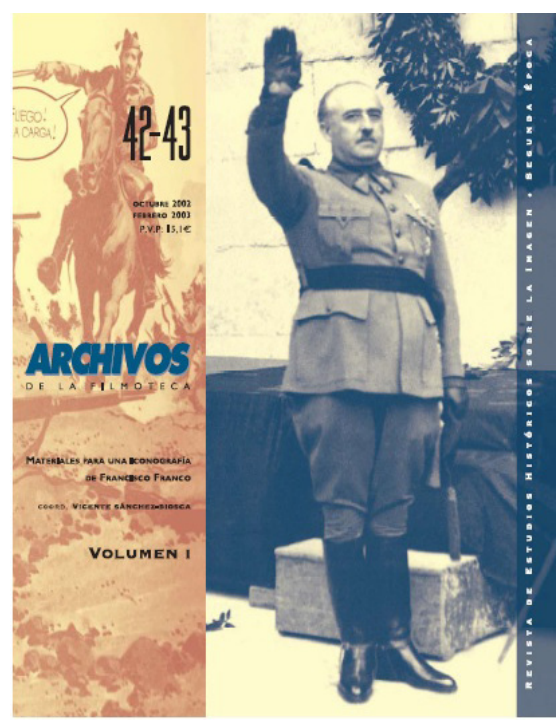

Vicente Sánchez-Biosca (coord.), «Materiales para una iconografía de Francisco Franco». Archivos de la filmoteca, n. $^{\circ}$ 42-43, 2002-2003.

El proyecto editorial más longevo e influyente de entre los emprendidos por el NFC es, sin duda, Contracampo (1979-1987). Después de sus 33 primeros números, la revista evoluciona, a mediados de los años ochenta, desde la atención a la actualidad a la publicación de corte académico. Pocas entregas más tarde, en el número $39^{7}$, comienza a editarse bajo el amparo del Instituto de Cine y Radiotelevisión de la Universitat de València. En esta segunda etapa priman los contenidos de fondo, en muchas ocasiones de cariz teórico y analítico, sobre los de actualidad y las secciones desaparecen, llegando los últimos números a estar confeccionados casi exclusivamente a partir de monográficos - «El discurso televisivo $»^{8} \mathrm{o}$ «Enunciación y punto de vista» ${ }^{9}-$.

Aunque no es un proyecto del NFC, Archivos de la Filmoteca bien puede ser vista - tanto por su fecha y lugar de nacimiento como por su orientación-como una suerte de continuación del trabajo emprendido por Contracampo durante su segunda época. Impulsada por Ricardo Muñoz Suay y editada por la Filmoteca de la Generalitat Valenciana, Archivos de la Filmoteca echa a andar en 1989 con el objetivo de crear una plataforma para difundir investigaciones relacionadas con el cine y el audiovisual en el marco del desarrollo de los estudios sobre ambas materias en las universidades españolas. Con colaboradores provenientes de Dirigido por -Esteve Riambau, José Enrique Monterde o Casimiro Torreiro- y Contracampo -Juan Miguel Company o Francisco Llinás-, arranca su

[7] Contracampo, $n .^{\text {o }} 39,1985$.

[8] VV.AA., «El discurso televisivo» (Contracampo, n. ${ }^{\circ} 39$, 1985).

[9] VV.AA., «Enunciación y punto de vista» (Contracampo, n. $\left.{ }^{\circ} 42,1987\right)$. 
[10] Archivos de la Filmoteca, n. ${ }^{\circ} 1,1989 ;$ n. ${ }^{\circ} 13,1992$.

[11] Archivos de la Filmoteca, n. ${ }^{\circ} 8,1990-1991$.

[12] VV. AA., «Propuestas para la escritura de una historia del cine español», (Archivos de la Filmoteca, n. ${ }^{\circ}$ 1, 1989), pp. $14-47$

[13] VV. AA., «Lo siniestro, la fotografía, el cine», (Archivos de la Filmoteca, n. ${ }^{\circ}$, 19901991), pp. 6-32.

[14] VV. AA., «Itinerarios del cine primitivo americano (1895-1915)», (Archivos de la Filmoteca, n. ${ }^{\circ}$ 2, 1989), pp. 76-114.

[15] VV. AA., «Una cita fuera de cuadro. Cine y pintura» (Archivos de la Filmoteca, n. ${ }^{0}$ 11, 1992), 48-109.

[16] VV. AA., «Sierra de Teruel, cincuenta años de esperanza», (Archivos de la Filmoteca, n. ${ }^{\circ}$ 3, 1989).

[17] Archivos de la filmoteca, n. ${ }^{\circ} 4,1990$. primera época -entre los números 1 y $13^{10}$ bajo la dirección hasta el número $8^{11}$ de otro antiguo colaborador de Contracampo, Vicente Ponce-, caracterizada fundamentalmente por artículos y reportajes de fondo que abordan diversos aspectos de la historia del cine, aunque compartiendo espacio con otros más próximos a la actualidad cinematográfica. Con todo, lo más característico de la publicación es la recuperación de importantes aportaciones a la reflexión sobre el cine y los dosieres de carácter monográfico compuestos por tres o cuatro artículos sobre distintas cuestiones relacionadas con el análisis fílmico o la historia del cine de las secciones «Hacer memoria, hacer historia» - «Propuestas para la escritura de una historia del cine español» ${ }^{12} \mathrm{o}$ «Lo siniestro, la fotografía, el cine» ${ }^{13}-\mathrm{y}$ «Avatares de la mirada» - «Itinerarios del cine primitivo americano (1895-1915) $»^{14} \mathrm{O}$ «Una cita fuera de cuadro. Cine y pintura» ${ }^{15}-$, que en ocasiones llegan a convertirse en números monográficos. Esto sucede con la conmemoración del cincuenta aniversario del rodaje de Sierra de Teruel (L'Espoir, André Malraux, 1939) ${ }^{16} \mathrm{o}$ con el estudio de la productora CIFESA en el número $4^{17}$.

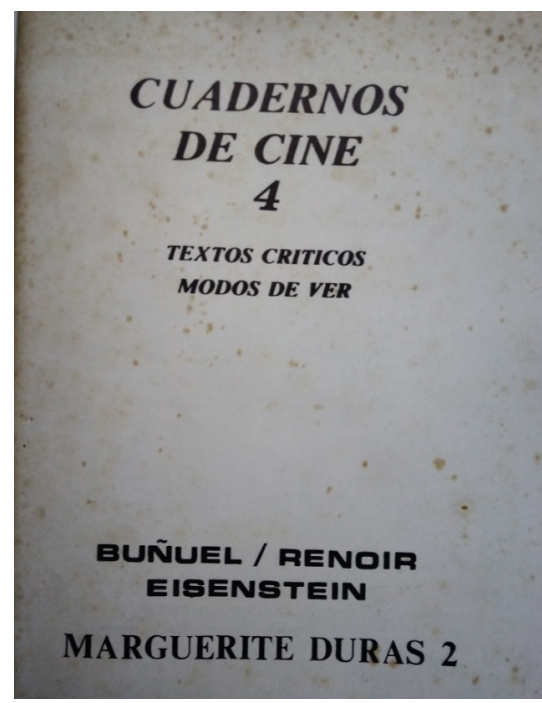

Cuadernos de cine. Textos críticos - Modos de ver n. ${ }^{\circ} 4,1984$.

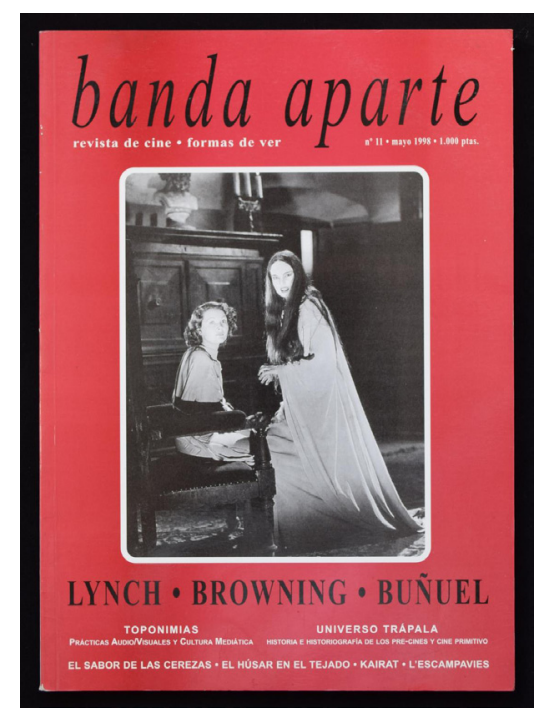

Banda Aparte. Revista de cine - Formas de ver, $\mathrm{n}^{\circ}$ $11,1998$.
No sería de recibo terminar este repaso a las publicaciones que tienen un pie en la academia sin consignar otros dos proyectos impulsados desde Valencia: Cuadernos de Cine. Textos críticos-Modos de ver y Banda Aparte. La primera publicará tan solo siete números entre 1981 y 1987 y estará estructurada a partir de números monográficos, excepto la última entrega que tendrá un carácter misceláneo. En ellos aparecen textos de producción propia firmados por Juan Miguel Company, Pau Esteve, Vicente Sánchez-Biosca o Santos Zun- 
zunegui, entre otros, y reproducciones de otros tantos autores de reconocido prestigio como Jacques Aumont, Roland Barthes, Pascal Bonitzer, Noël Burch, Edgar Morin o Jean Pierre Oudart. Cuadernos de Cine ocupa el mismo espacio editorial e intereses que el Contracampo más académico, llegando incluso a compartir colaboradores.

Ya en la década siguiente -en concreto, entre 1994 y 2001- Ediciones de la Mirada publica Banda Aparte. Revista de cine/Formas de Ver. Que la mayoría de los colaboradores e integrantes de su consejo de redacción provengan del ámbito universitario advierte ya del carácter híbrido de la revista: Luis Alonso García, Txomin Ansola, Vicente José Benet, Juan Miguel Company, Carlos A. Cuéllar, Arturo Lozano Aguilar, José Antonio Palao, Pilar Pedraza, Jesús González Requena, Vicente Sánchez-Biosca, Virginia Villaplana, Imanol Zumalde o Santos Zunzunegui. Tras unos números iniciales en los que se combinan las misceláneas con los monográficos dedicados a cineastas, la revista adquiere una composición en secciones fijas. Entre ellas destacan «Reencuadres» $\mathrm{y}$ «Universo Trápala». La primera aborda desde distintas perspectivas la filmografía de directores relevantes -David Lynch y Tod Browning ${ }^{18}$, Marc Recha ${ }^{19} \mathrm{o}$ Agnès Var$\mathrm{da}^{20}$-, aunque con el tiempo también trata algunas cinematografías nacionales prestigiosas - «Cine iraní»» ${ }^{21}$, géneros como el cine pornográfico ${ }^{22} \mathrm{o}$ las diferentes formas en las que el cine se ha aproximado a la clase obrera ${ }^{23}$, por ejemplo. La historia del cine tiene su espacio en «Universo Trápala». En esta sección caben sobre todo aproximaciones al pre-cine y al cine primitivo.

A partir de Banda Aparte, y muchas veces con los mismos colaboradores, Ediciones de la Mirada, bajo la dirección de Jesús Rodrigo, crea varias coleccio-

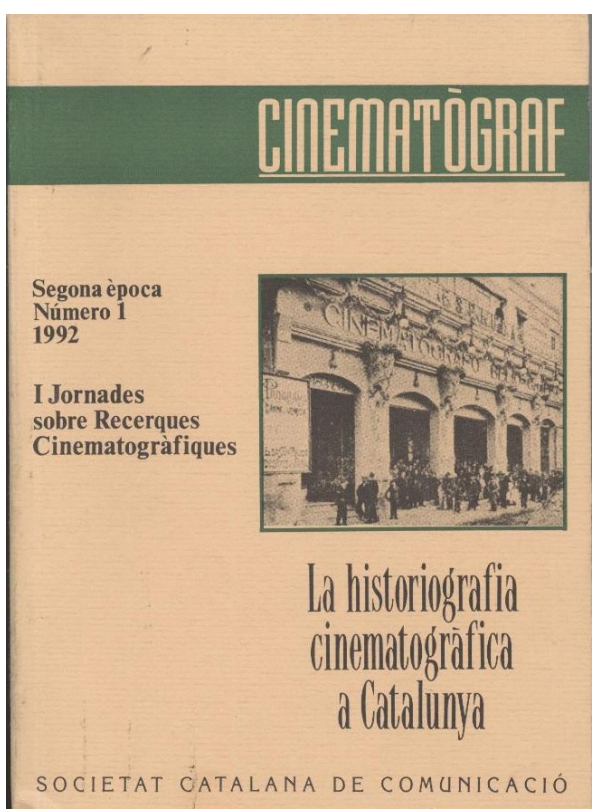
nes de libros sobre cine, que han tenido continuidad en Shangrila Ediciones. Esta última está difundiendo muchas e importantes investigaciones que no encuentran acomodo en otras editoriales, además de adquirir cada vez más prestigio, como demuestran los importantes premios que en su corta vida ya ha recibido ${ }^{24}$.

\section{Las revistas académicas sobre cine ${ }^{25}$}

Si bien las cabeceras mencionadas hasta aquí evolucionan desde las revistas especializadas hasta las académicas, la primera publicación inequívocamente
[18] VV. AA., «Reencuadres: David Lynch-Tod Browning» (Banda Aparte, n. ${ }^{0}$ 11, 1998), pp. 15-52.

[19] VV. AA., "Reencuadres: Marc Recha» (Banda Aparte, n. ${ }^{\circ}$ 14-15, 1999), pp. 20-34.

[2o] VV. AA., «Reencuadres: Agnès Varda» (Banda Aparte, n. $\left.{ }^{\circ} 19,2000\right)$, pp. 19-46.

[21] VV. AA., «Reencuadres: Cine iraní» (Banda Aparte, n. ${ }^{\circ}$ 16, 1999), pp.74-91.

[22] VV. AA., «Reencuadres: La imagen pornográfica» (Banda Aparte, n. ${ }^{\circ}$ 19, 200o), pp. 47-75.

[23] VV. AA., «Reencuadres: Cine y Clase Obrera» (Banda Aparte, n. $\left.{ }^{0} 17,2000\right)$, pp. 1746.

[24] Jesús Rodrigo García, «Ediciones de la Mirada» (Métodos de Información, n. ${ }^{\circ} 7$, 2000), pp. 38-39.

[25] Para un análisis más detallado y en su contexto de estas publicaciones, véase Jorge Nieto Ferrando y José Enrique Monterde, La prensa cinematográfica en España, 19102010 (Santander, Shangrila, 2018) y Jorge Nieto Ferrando, «La prensa cinematográfica española como fuente y objeto de la historia del cine. Análisis y evolución de sus contenidos (1910-2010)" (Historia y Comunicación Social, n. ${ }^{\circ} 24$, vol. 1, 2019), pp. 237-258. 
[26] A. Amorós, «Els estudis cinematogràfics Orphea», (Cinematògraf, época I, n. ${ }^{\circ}{ }_{1}$, 1983-1984), pp. 69-102.

[27] Joan M. Minguet Batllori, «El noucentisme contra el cinematògraf (La campanya anticinematogràfica de la revista $\mathrm{Ca}$ taluña)» (Cinematògraf, época I, n. $\left.{ }^{\circ} 3,1985-1986\right)$, pp.21-68.

[28] Palmira Gonzalez, «Studio Films. La productora més comercial del cinema mut a Catalunya (1915-1922)» (Cinematògraf, época I, n. ${ }^{\circ}$ 2, 19841985), pp. 111-131.

[29] Joaquim Romaguera i Ramió, "Seixanta anys de la "Biblioteca del Cinema Delmiro de Caralt"» (Cinematògraf, época I, n. $\left.{ }^{\circ} 2,1984-1985\right)$, pp. 199-232.

[3o] Enric Ripoll-Freixes, " "Cercle Lumiere", cine-club de l'Institut Francès de Barcelona" (Cinematògraf, época I, n.$^{\circ}$, 1984-1985), p. 277-304.

[31] VV. AA., «La historiografia cinematogràfica a Catalunya» (Cinematògraf, época II, n. ${ }^{0} 1$, 1992).

[32] VV. AA., «Infraestructures industrials» (Cinematògraf, época II, n. $\left.{ }^{0} 2,1995\right)$.

[33] VV. AA., «El cinema espanyol, de l'adveniment i la implantació del cinema sonor (1929) a l'esclat de la guerra civil» (Cinematògraf, época II, n. $\left.{ }^{\circ} 3,2001\right)$. dedicada a dar difusión a trabajos de investigación sobre cine es Cinematògraf, que se publica en Barcelona con una periodicidad muy irregular entre 1983 y 2001. Editada en un primer momento por la Federació Catalana de Cineclubs, cuenta con colaboradores como Jordi Balló, Josep Maria Caparrós Lera, Josep Lluís Fecé, Palmira González López, Mercè Ibarz, Josep Lluís i Falcó, Joan Minguet Batllori, Miquel Porter, Àngel Quintana, Joaquim Romaguera i Ramió (su director), Marta Selva, Anna Solà o Josep Torrella, entre otros. La revista nace con la intención de estimular los estudios sobre el cine catalán. La primera época se articula alrededor de los textos seleccionados en los cuatro concursos Història de la Catalunya cinematogràfica, que se recogen en el primer gran apartado de cada número. Entre estos artículos destacan «Els estudis cinematogràfics Orphea» ${ }^{26} \mathrm{O}$ «El noucentisme contra el cinematògraf (La campanya anticinematogràfica de la revista Cataluña)» ${ }^{27}$. Los otros apartados están dedicados fundamentalmente a la historia de la industria cinematográfica catalana - «Studio Films. La productora més comercial del cinema mut a Catalunya (1915-1922)» ${ }^{28}$, por ejemplo-, el estudio de determinados personajes destacados - «Seixanta anys de la "Biblioteca del Cinema Delmiro de Caral" $t »{ }^{29}-$ o el cineclubismo - "“Cercle Lumiere", cine-club de l'Institut Francès de Barcelona» ${ }^{30}$, por ejemplo-, entre otros temas.

La segunda época de Cinematògraf, editada por la Societat Catalana de Comunicació, perteneciente al Institut d'Estudis Catalans, se encarga de recoger las actas de las Jornades sobre recerques cinematogràfiques. Esta época muestra el mismo cariz que la anterior, se organiza en monográficos - «La historiografia cinematogràfica a Catalunya» ${ }^{31}$, «Infraestructures industrials» ${ }^{2} \mathrm{y}$ «El cinema espanyol, de l'adveniment i la implantació del cinema sonor (1929) a l'esclat de la guerra civil»33-, además de abrirse poco a poco a aspectos relacionados con la historia del cine en el estado español.

En la línea de Cinematòfraf aparece en 1985 Ikusgaiak. Cuadernos de Cinematografía. Publicada y auspiciada por la sociedad de estudios Vascos/ Eusko Ikaskuntza, está dedicada fundamentalmente a la historia del cine en Navarra y el País Vas-

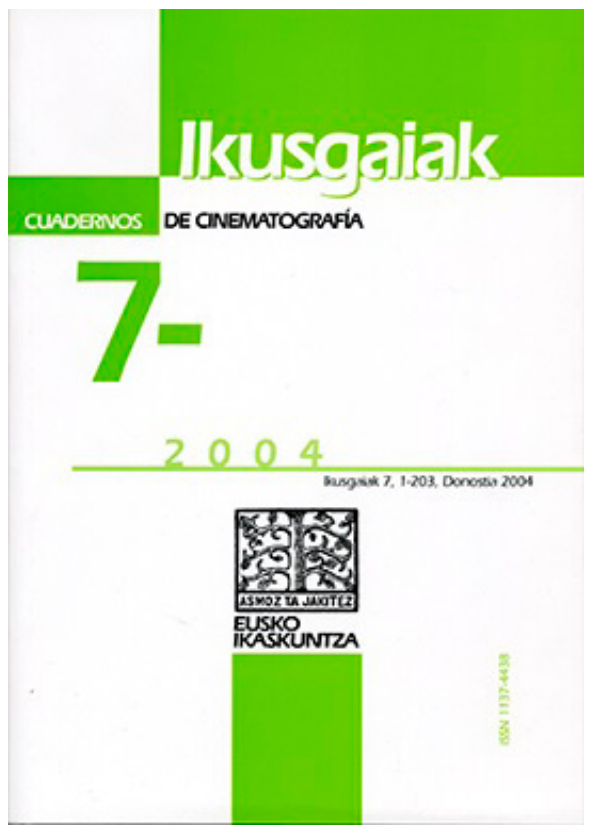

Ikusgaiak. Cuadernos de cinematografía, n. ${ }^{\circ}$ 7, 2004. 
co. Los primeros tres números son los monográficos «El cine y los vascos» ${ }^{34}$, «Sombras de la caverna. El tempo vasco en el cine» ${ }^{35} \mathrm{y}$ «El cine del País Vasco. De Amalur (1968) a Airbag (1997)» ${ }^{36}$. A partir de la cuarta entrega, sin embargo, la revista tiene carácter misceláneo. En esta etapa aparecen estudios sobre películas como Arrebato (Iván Zulueta, 1980) ${ }^{37}$ o El día de la Bestia (Alex de la Iglesia, 1995 $)^{38}$, aproximaciones a la obra de cineastas como Víctor Erice ${ }^{39} \mathrm{o}$ Julio Medem ${ }^{40}$ y textos de cariz historiográfico sobre la política cinematográfica en el País Vasco ${ }^{41}$ o la exhibición ${ }^{42}$. Firman colaboraciones en la revista Luis Alonso García, Asier Aranzubia, Igor Barrenetxea Marañón, Emeterio Diez Puertas, Zigor Etxebeste Gómez, Leire Ituarte Pérez, Jon Letamendi, Miguel Ángel Lomillos, Carlos Losilla, Julio Montero o Jean-Claude Seguin. La revista continúa editándose en la actualidad, pero desde 1985 solo ha publicado ocho números.

En 1993 arranca la segunda etapa de Archivos de la Filmoteca -ahora bajo la dirección de Vicente Sánchez-Biosca y Vicente Benet-, que busca con más claridad al lector académico y al investigador, aunque presenta cierta continuidad con la anterior en su estructura y secciones — «Historia y documentos», «Recuperación y arqueología», «Teoría y estética» y «Universo electrónico»-, la importancia de los dosieres y monográficos y la reedición de textos sobre cine poco conocidos de autores clave en el panorama cultural, literario o filosófico -Erwin Panofsky ${ }^{43}$ o Georg Lukács ${ }^{44}$, entre otros-. La diferencia con la anterior reside en el abandono de las referencias a la actualidad. Con el tiempo, además, las secciones dejan a un lado su carácter misceláneo para formar conjuntos de artículos agrupados por su temática que, más tarde, -desde el número 27 (1997) - confeccionan bloques independientes: «La imagen del Alcázar en la mitología franquista» ${ }^{45}$, «Carmen en Hollywood» ${ }^{46} \mathrm{o}$ «Cine y revolución cubana. Luces y sombras» ${ }^{47}$, por ejemplo, coordinados por diferentes especialistas. Respecto a los números monográficos, destacan «Las estrellas. Un mito en la era de la razón» ${ }^{48}$, «Mitologías latinoamericanas» ${ }^{49}$ y muy especialmente «Materiales para una iconografía de Francisco Franco» ${ }^{50}$, coordinado por Vicente Sánchez-Biosca.
[34] José María Unsain, «El cine y los vascos» (Ikusgaiak. Cuadernos de Cinematografía, n. $\left.{ }^{\circ} 1,1985\right)$.

[35] Juan Miguel Gutiérrez Márquez, «Sombras de la caverna. El tempo vasco en el cine» (Ikusgaiak, n. ${ }^{\circ}$ 2, 1997).

[36] Carlos Roldán Larreta, «El cine del País Vasco. De Amalur (1968) a Airbag (1997)» (Ikusgaiak, n. ${ }^{\circ} 3$, 1999).

[37] Garikoitz Gamarra Quintanilla, «A propósito de Arrebato: Ascética y Cultura Pop» (Ikusgaiak, n. ${ }^{\circ} 5$, 2001), pp. 37-63.

[38] Leire Ituarte Pérez, «Breve inventario del imaginario posmoderno en El día de la Bestia: proyecciones utópicas de una distopia urbana» (Ikusgaiak, $\left.\mathrm{n}^{0} 7,2004\right)$, pp. 125-136.

[39] Miguel Ángel Lomillos, «La concepción y experiencia del cine en la obra de Víctor Erice» (Ikusgaiak, n. ${ }^{\circ}$ 6, 2003), pp. 37-6o.

[4o] Zigor Etxebeste Gómez, «Julio Medem, a través del espejo de la realidad» (Ikusgaiak, n. ${ }^{\circ} 6$, 2003), pp. 117-134.

[41] Emeterio Díez, «La política cinematográfica del primer gobierno de Euskadi: la gerencia de espectáculos púbicos (1936-1937)» (Ikusgaiak, n. ${ }^{\circ}$ 5, 2001) pp. 117-132.

[42] Txomin Ansola, «Crisis y recuperación de la exhibición cinematográfica en Barakaldo (1980-1997) (Ikusgaiak, n. 4, 2000 ), pp. 151-164.

[43] Erwin Panofsky, «El estilo y el medio en la imagen cinematográfica» (Archivos de la Filmoteca, n. ${ }^{\circ}$ 35, 2000), pp. 158-177.

[44] Georg Lukács, «Reflexiones sobre una estética del cine» (Archivos de la Filmoteca, n. ${ }^{0}$ 37, 2001), pp. 134-140.

[45] Vicente Sánchez-Biosca (coord.), «La imagen del Alcázar en la mitología franquista» (Archivos de la Filmoteca, n. ${ }^{\circ}$ 35, 2000 ), pp. 45-156.

[46] Gloria F. Vilches (coord.), «Carmen en Hollywood» (Archivos de la Filmoteca, n. ${ }^{0}$ 51, 2005), pp. 9-108.

[47] Nancy Berthier (coord.), «Cine y revolución cubana. Luces y sombras» (Archivos de la Filmoteca, n. ${ }^{\circ}$ 59, 2008), pp. 6-219.

[48] Vicente J. Benet y Vicente Sánchez-Biosca (coords.), (Archivos de la Filmoteca, n. ${ }^{\circ}$ 18, 1994)

[49] Alberto Elena y Paulo Antonio Paranaguá (coords.), «Mitologías latinoamericanas» (Archivos de la Filmoteca, n. ${ }^{\circ}$ 31, 1999).

[50] Vicente Sánchez-Biosca (coord.), «Materiales para una iconografía de Francisco Franco» (Archivos de la Filmoteca, n. ${ }^{\circ}$ 42-43, 2002-2003). 
[51] Filmhistoria, n. ${ }^{\circ}$ II, vol. 3, 1992.

[52] Filmhistoria, n. ${ }^{\circ}$ VI, vol. 1,1996 y n. ${ }^{\circ}$ VIII, vol. 1, 1998.

[53] Filmhistoria, n. ${ }^{\circ}$ VII, vol. 2,1997 .

[54] Sergio Alegre, «Re-lectura de La Grande Illusion (1937)» (Filmhistoria, n. ${ }^{\circ}$ I, vol. 1 , 1991), pp. 25-34.
La tercera etapa de la revista comienza con la llegada a su dirección de Francisco Javier Gómez Tarín en el número 70 (2012) y el objetivo de ajustar la revista a los estándares de las publicaciones académicas. Los cambios se aprecian en la introducción de la sección «Filmotecas», dedicada al análisis de diversas cuestiones relacionadas con la preservación y divulgación del patrimonio audiovisual que gestionan los diferentes archivos fílmicos, la reducción de los dosieres a uno en exclusiva por número, aunque mucho más extenso y con un vínculo más laxo con la historia del cine y del audiovisual, y la inclusión de «Fuera de Cuadro», apartado de carácter misceláneo que contiene los artículos que no tienen cabida en el dosier. Esta etapa concluye abruptamente en el número 72 (2013), aunque recientemente (2017) se ha reactivado la revista bajo la dirección de Agustín Rubio. El espíritu es continuista con respecto a la última etapa, con la única novedad relevante de la introducción de una sección de Historia Oral. En las páginas de Archivos de la Filmoteca pueden encontrarse las firmas de buena parte de los investigadores más relevantes en el campo del audiovisual y los estudios fílmicos.

En la década de los noventa en Cataluña aparecen dos revistas importantes: Filmhistoria y Cinema Rescat. La primera nace en 1991, publicándose en papel hasta 2000 y, desde 2001, en versión digital. Esta revista es el órgano del Centre d'Investigacions Film-Història, colectivo fundado en 1983 -refundado en 2000 como grupo de investigación de la Universitat de Barcelona- por José María Caparrós Lera dedicado a la investigación sobre el cine como fuente histórica, testimonio de la sociedad e instrumento didáctico de las ciencias sociales y de las humanidades. Compartiendo estos objetivos, y con la firma de reconocidos especialistas internacionales en la materia como Pierre Sorlin, Marc Ferro o Robert Rosenstone, además de los miembros del propio centro y de otros investigadores, la revista destaca por azuzar el debate teórico y metodológico acerca de las relaciones entre el cine y la historia y estudiar el tratamiento cinematográfico que han recibido determinados acontecimientos como el descubrimiento y colonización de América $^{51}$, la guerra de Vietnam ${ }^{52}$ o la reunificación de Alemania ${ }^{53}$. Desde la misma perspectiva se analizan determinadas películas -La gran ilusión (La grande illusion, Jean Renoir, 1937) $)^{54}, L^{-}$- Filmhistoria, n. ${ }^{\circ}$ 1, vol. 1, 1991. 
bertarias (Vicente Aranda, 1996) ${ }^{55}$, etc.- y la obra de algunos cineastas susceptibles de encajar en los parámetros historiográficos de la publicación, tanto por el cariz social de su filmografía como por su capacidad para reflejar la sociedad en la que desarrollan su actividad o los usos de la historia en ella. Así sucede con Basilio Martín Patino ${ }^{56}$ o Elia Kazan ${ }^{57}$, por poner dos ejemplos. Los contenidos de la revista se completan con secciones dedicadas a la actualidad, en concreto a los estrenos recientes, criticados desde su particular forma de abordar el hecho cinematográfico, a las novedades bibliográficas y a las noticias relacionadas con congresos, reuniones y seminarios. Su edición digital desde 2001 mantiene las líneas básicas de la publicación en papel. Aparte de la revista, el Centre d'Investigacions Film-Història también publica trabajos de carácter monográfico como Cine español. Una historia por autonomías ${ }^{5}$ o Brumas del franquismo. El auge del cine negro español (1950-1965)59, además de impartir conferencias, cursos y colaboraciones de diverso tipo con otras instituciones.

Cinema Rescat. Butlletí de L'associació Catalana per a la Recerca i Recuperació del Patrimoni Cinematogràfic, publicada en Mataró entre 1996 y 2007, es el órgano de la asociación del mismo nombre cuyo objetivo es la recuperación, investigación, conservación y difusión del patrimonio cinematográfico. Tanto por sus contenidos como por las firmas que aparecen en sus páginas -Ferran Alberich, Alfonso Del Amo, Jordi Artigas, Josep Oriol Bassa, Mariona Bruzzo Llaberia, Antoni Kirchner, Josep Lluís i Falcó, Tomàs Mallol, Joan

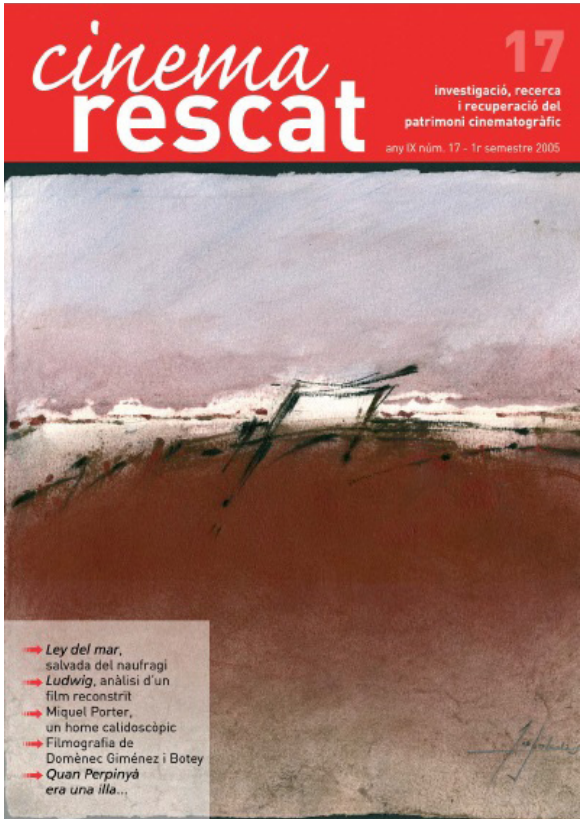

Cinema Rescat. Bulletí de I'Associació Catalana per a la Recerca i Recuperació del Patrimoni Cinematogràfic, n. ${ }^{\circ} 17,2005$.
Minguet-Batllori, Miquel Porter, Àngel Quintana o Encarnació Soler i Alomà- la revista está a medio camino entre los intereses de una publicación de filmoteca y las académicas. Sus contenidos se organizan siguiendo fundamentalmente las secciones «Opinions», «Ressons de l'arxiu de la Filmoteca», «Tecnologia i cinema» $\mathrm{y}$ «Nous tresors» - aunque sus nombres cambian con el tiempo manteniendo los mismos contenidos-, a las que hay que añadir las noticias relacionadas con esta asociación y otras afines. Desde la primera entrega la revista reflexiona sobre el valor de la conservación y la difusión del patrimonio cinematográfico. Destaca, sobre todo, la creación del Museu del cinema de Girona, que
[55] Magi Crusells, «Libertarias: la utopía durante la Guerra Civil española no fue solo cosa de hombres» (Filmhistoria, n. ${ }^{\circ}$ VI, vol. 3, 1996), pp. 295-300.

[56] Fernando González, «Basilio Martín Patino: pensar la Historia» (Filmhistoria, n. ${ }^{\circ}$ VII, vol. 2, 1997), pp. 141-160.

[57] Efrén Cuevas, «La sociedad estadounidense bajo la mirada de Elia Kazan» (Filmhistoria, n. ${ }^{\circ}$ VIII, vol. 1, 1998), pp. 29-49.

[58] José María Caparrós Lera (coord.), Cine español. Una historia por autonomías (Vol. I y II) (Barcelona, Promociones y publicaciones universitarias, 1996).

[59] Francesc Sánchez Barba, Brumas del franquismo. El auge del cine negro español (1950-1965) (Barcelona, Universitat de Barcelona, 2007). 
protagoniza la sección «Opinions» del número 4 en su totalidad ${ }^{60}$. Pronto, sin embargo, intercala el tratamiento de cuestiones relacionadas con los archivos y la documentación con otras más propias de la historia del cine. Así sucede en el número 5, dedicado al cine y la Guerra Civil ${ }^{61}$. En entregas posteriores se aborda el amateurismo ${ }^{62}$, tema especialmente apreciado por los redactores de la revista, o la figura de Segundo de Chomón ${ }^{63}$. Las secciones «Ressons de l'arxiu de la Filmoteca» y «Tecnologia y cinema» recogen diferentes iniciativas en el ámbito de la catalogación y la recuperación del patrimonio cinematográfico. Como su nombre indica, «Nous tresors» está centrada en destacar novedades relacionadas con la investigación de la historia del cine catalán, así como con la aparición de nuevas fuentes documentales o películas destacables. A estas secciones se une con el tiempo «Catàleg», que da a conocer archivos relativamente desconocidos, y otras de aparición más irregular como «Homenatge» o «Diàlegs». Ambas informan sobre las actividades de relevantes investigadores, coleccionistas y profesionales.

En 1994 surge una de las revistas que más reconocimientos ha cosechado entre los investigadores: Secuencias. Revista de historia del cine, fundada y dirigida por Alberto Elena en un primer momento, al que siguieron Daniel Sánchez Salas y María Luisa Ortega; revista en la que han publicado prácticamente todos los investigadores más reconocidos en los últimos veinte años. Secuencias, que comparte muchos puntos en común con las primeras etapas de Archivos de la Filmoteca, surge también al calor del importante desarrollo de los estudios sobre cine -más específicamente de historia del cine- en el

[6o] Cinema Rescat, $\mathrm{n}^{\mathrm{o}} 4$, 1998.

[61] VV. AA., «Especial Guerra Civil i cinema» (Cinema Rescat, $\left.\mathrm{n}^{\circ} 5,1998\right)$.

[62] VV. AA., "75è aniversari del naixement del cinema amateur» (Cinema Rescat, n. ${ }^{\circ}$ 6, 1998), pp. 5-24 y VV.AA., «Especial cinema no professional - Cinema amateur», (Cinema Rescat, n. ${ }^{\circ} 7,1999$ ).

[63] VV. AA., «Especial Segundo de Chomón» (Cinema Rescat, n. ${ }^{\circ}$ 9, 2000).

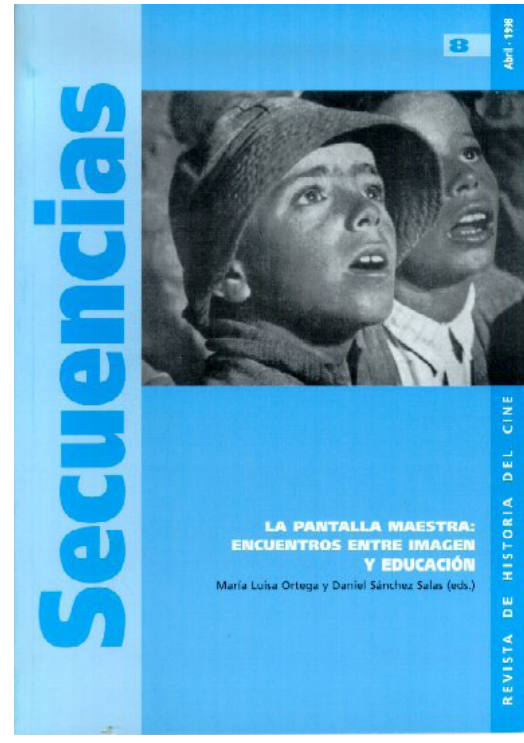

María Luisa Ortega y Daniel Sánchez Salas (eds.), "La pantalla maestra: encuentros entre imagen y educación». Secuencias. Revista de historia del cine, . $^{\circ} 8,1998$.

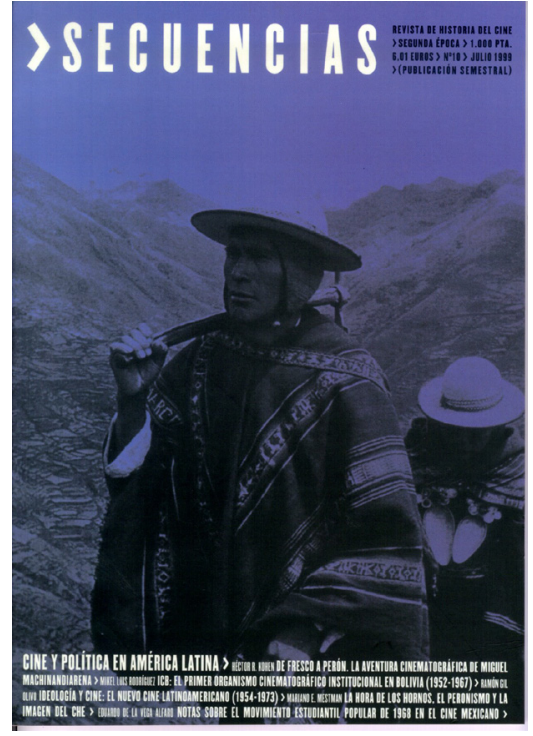

VV.AA., "Cine y política en América Latina». Secuencias, n. ${ }^{\circ} 10,1999$. 


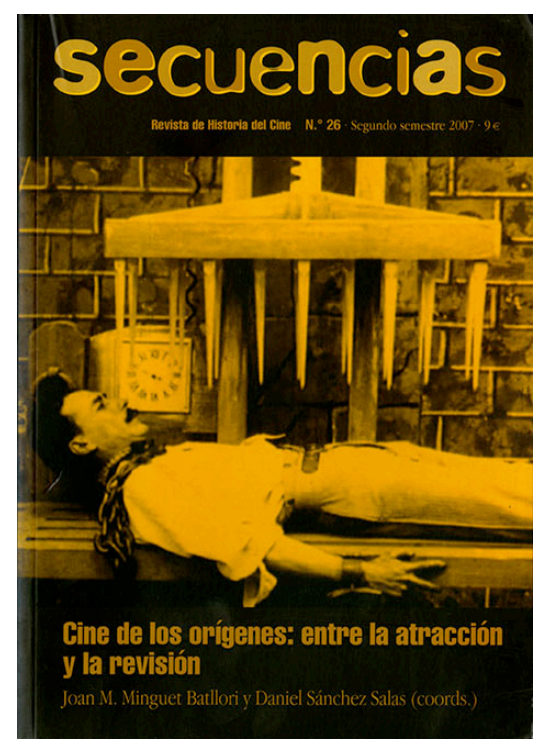

Joan M. Minguet Batllori y Daniel Sánchez Salas (coords.), "Cine de los orígenes: entre la atracción y la revisión». Secuencias, n. ${ }^{\circ}$ 26, 2007.

ámbito académico español de los años noventa. Su objetivo, tal como señala el editorial del número $1^{64}$, es contribuir a la creación de canales de expresión adecuados para difundir las investigaciones recientes en este ámbito y «suministrar un foro de discusión a los historiadores del cine».

Desde un principio la revista está dividida en las secciones "Artículos», «Notas» ${ }^{65} \mathrm{y}$ «Libros», esta última dedicada a las novedades editoriales sobre cine. Mientras la primera contiene estudios extensos, la segunda aporta breves textos de reflexión sobre aspectos relacionados con el cine y su historia. Sobre todo en los primeros números, en la sección «Notas» aparecen artículos acerca de los archivos y la documentación cinematográfica - «Los archivos de la unión soviética» ${ }^{6}-$, así como cuestiones de historiografía — «David Bordwell, el "modo de práctica fílmica” y la reciente historiografía del cine en España» ${ }^{67}$. Más tarde se centra fundamentalmente en noticias sobre actividades académicas, asociativas - como los distintos congresos de la Asociación Española de Historiadores del Cine- o las retrospectivas y la presencia de determinadas cinematografías en los festivales de cine.

Los contenidos de la sección «Artículos» están enfocados en el tratamiento documentado de aspectos poco conocidos de la historia del cine, sin descartar el análisis fílmico o la reflexión acerca de los géneros y la teoría del cine. Destaca la atención al cine español en textos como «El último caído de Sáenz de Heredia, un poema documental sobre Franco ${ }^{68}$, «¿Quién prohibió Rojo y negro?» ${ }^{69}$, «El cine español según Goebbels. Apuntes sobre la versión alemana de Carmen la de Triana» $^{70}$, por citar algunos ejemplos.
[64] Secuencias. Revista de historia del cine, n. ${ }^{0} 1,1994$.

[65] [Nota de los editores] La sección «Notas» en su formato habitual se publicó por última vez en el número 32 de Secuencias.

[66] Clara López Rubio y Wolf Martin Hamdorf, «Los archivos de la Unión Soviética. Entrevista a Naum Kleiman» (Secuencias, n. $\left.{ }^{\circ} 2,1995\right)$, pp. 81-94.

[67] José Luis Castro de Paz, «David Bordwell, el "modo de práctica fílmica” y la reciente historiografía del cine en España» (Secuencias, n. ${ }^{\circ}$ 3, 1995), pp.111-114.

[68] Nancy Berthier, «El último caído de Sáenz de Heredia, un poema documental sobre Franco» (Secuencias, n. ${ }^{\circ}$, 1995), pp. 9-29.

[69] Alberto Elena, «¿Quién prohibió Rojo y negro?» (Secuencias, n. ${ }^{\circ}$, 1997), pp. 6378.

[7o] Marta Muñoz Aunión, «El cine español según Goebbels. Apuntes sobre la versión alemana de Carmen la de Triana» (Secuencias, n. ${ }^{\circ}$ 20, 2004), pp. 25-46. 
[71] Marina Díaz (ed.), "Cine y política en América Latina» (Secuencias, n. ${ }^{0}$ 10, 1999).

[72] Valeria Camporesi y Eva Parrondo Coppel (eds.), «Cine y mujer. (Re)visiones feministas» (Secuencias, n. ${ }^{0} 15,2002$ ).

[73] Alberto Elena (ed.), «Cine y migraciones. La experiencia hispanoamericana» (Secuencias, . $^{\circ} 22,2005$ )

[74] Alberto Elena y Helio San Miguel (eds.), «El nuevo Bollywood» (Secuencias, n. ${ }^{\circ} 36$, 2012)

[75] Véase Andrés Peláez Páez, «Las publicaciones», en Daniel Sánchez Salas y Bernardo Sánchez Salas (coords.), «Doce. Historia de la academia, 19861998" (Cuadernos de la Academia, n. ${ }^{\circ} 4$, 1998), pp. 91-112.

[76] Román Gubern (coord.), "Un siglo de cine en España» (Cuadernos de la Academia, n. $\left.{ }^{\circ} 1,1997\right)$.

[77] Josetxo Cerdán y Julio Pérez Perucha, «Tras el sueño» (Cuadernos de la Academia, n. $\left.{ }^{0} 2,1998\right)$.

[78] VV.AA., «Los límites de la frontera. La coproducción en el cine español», (Cuadernos de la Academia, n. ${ }^{\circ} 5$, 1999).

[79] Luis Fernández Colorado y Pilar Couto Cantero (coords.). «La herida de las sombras. el cine español en los años cuarenta» (Cuadernos de la Academia, n. ${ }^{\circ} 9$, 2001).

[8o] Arturo Lozano Aguilar y Julio Pérez Perucha (eds.), «El cine español durante la transición democrática (1974-1983)» (Cuadernos de la Academia, n. $\left.{ }^{\circ} 13-14,2005\right)$.

Desde el número 8 (1998) Secuencias intercala números misceláneos con otros de carácter monográfico. Respecto a estos últimos, algunos ejemplos son «Cine y política en América Latina ${ }^{71}$, «Cine y mujer. (Re) visiones feministas $»^{72} \mathrm{O}$ «Cine y migraciones. La experiencia hispanoamericana» ${ }^{73}$. También son importantes las aproximaciones a las denominadas cinematografías «periféricas» como, por ejemplo, el cine indio: «El nuevo Bollywood» ${ }^{74}$.

Todavía en la década de los noventa debemos señalar una revista importarte: Cuadernos de la Academia, que aparece en 1997 y está en activo hasta 2005. Tercera de las publicaciones editadas por la Academia de las Artes

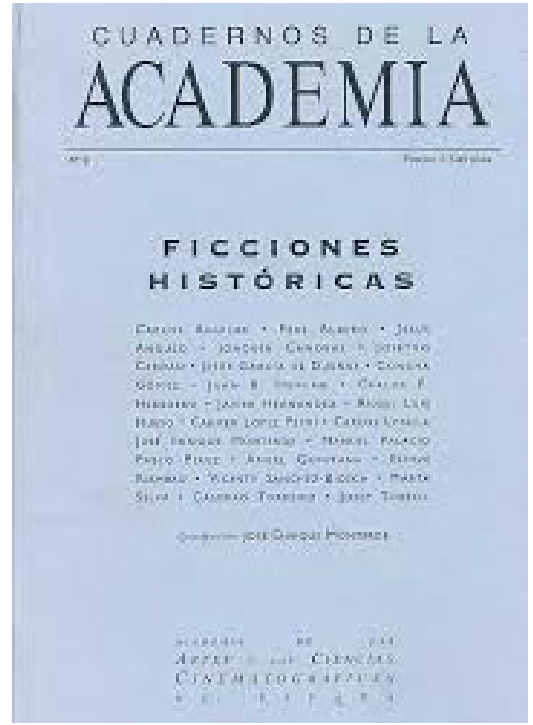

"Ficciones históricas». Cuadernos de la Academia, n. ${ }^{\circ}$ 6, 1999 y las Ciencias Cinematográficas de España - las dos primeras son Academia. Revista del Cine Español y el boletín de la institución: Academia. Noticias del Cine Español ${ }^{75}$-, nace en el marco de las conmemoraciones por el centenario del nacimiento del cinematógrafo y centra su interés en el cine español desde una perspectiva historiográfica. Sus números son monográficos, coordinados por uno o dos historiadores del cine. Las dos entregas iniciales — «Un siglo de cine en España» ${ }^{76}$, coordinada por Román Gubern, y «Tras el sueño»77, coordinada por Josetxo Cerdán y Julio Pérez Perucha - tienen como nexo de unión el centenario del cinematógrafo. La segunda, además, inicia una fructífera colaboración con la Asociación Española de Historiadores del Cine que convierte a la revista en uno de los canales de difusión de las actas de sus congresos bienales. Así, Cuadernos de la Academia publica «Los límites de la frontera. La coproducción en el cine español» ${ }^{78}$, «La herida de las sombras. El cine español en los años cuarenta» ${ }^{79} \mathrm{O}$ «El cine español durante la transición democrática» ${ }^{80}$. El resto de monográficos son una singular «historia oral» del cine - «Memoria viva del cine español» ${ }^{81}-$, un homenaje a Luis Buñuel en el centenario de su nacimiento - «En torno a Buñuel» ${ }^{82}-$, un acercamiento a la historia de los estudios cinematográficos españoles — «os estudios cinematográficos españoles» ${ }^{8}-$, aproximaciones a las relaciones que el cine guarda

[81] Emilio C. García Fernández, «Memoria viva del cine español» (Cuadernos de la Academia, n. ${ }^{\circ}$ 3, 1998).

[82] Marisol Carnicero y Daniel Sánchez Salas (eds.), «En torno a Buñuel» (Cuadernos de la Academia, n..$^{0}$ 7-8, 2000).

[83] Jesús García de Dueñas y Jorge Gorostiza (eds.), «Los estudios cinematográficos españoles» (Cuadernos de la Academia, n. ${ }^{\circ}$ 10, 2001). 
con la historia-«Ficciones históricas» ${ }^{84}-\mathrm{y}$ las adaptaciones literarias — «La imprenta dinámica. Literatura española en el cine español» ${ }^{85}-$ o el repaso a la propia trayectoria de la academia — «Doce. Historia de la academia» ${ }^{86}-$.

En la década de 2000 aparecen cinco revistas destacables: Latente, Quaderni del CSCI, Quaderns de Cine, Metakinema y L'Atalante. Latente. Revista de Historia y Estética del Audiovisual nace en Santa Cruz de Tenerife en 2003. De periodicidad anual y publicada por el Servicio de Publicaciones de la Universidad de la Laguna, está orientada fundamentalmente a dar salida a investigaciones en el ámbito de los medios audiovisuales y, dentro de ellos, sobre todo al cine. Algunas entregas presentan dosieres monográficos. Cada número destina también un apartado a la reseña de libros.

Quaderni del CSCI. Rivista Annuale di Cinema Italiano es una singular revista trilingüe -italiano, español y catalán, aunque predomine la primera lengua- publicada por el Instituto Italiano de Cultura de Barcelona desde 2005. Su objetivo es la promoción de las investigaciones sobre cine italiano en España. Para ello convoca de manera regular premios a artículos y reseñas. La revista tiene fundamentalmente carácter monográfico, y sus entregas están dedicadas a Federico Fellini ${ }^{87}$, el documental en Italia ${ }^{88}$ o el tratamiento de las guerras en el cine italiano ${ }^{89}$, aunque también reserva unas páginas finales de carácter misceláneo. En ellas destacan, junto a los ensayos premiados, algunos artículos sobre las relaciones entre el cine italiano y el producido en los ámbitos hispanohablantes: "Producciones cinematográficas hispano-italianas»" ${ }^{\circ 0}$ "L'assedio dell'Alcazar/ Sin novedad en el Alcázar (1940), de Augusto Genina. Análisis de la película restaurada» $»^{91} \mathrm{O}$ «Presencia del cine italiano en el cine mudo mexicano» ${ }^{92}$.

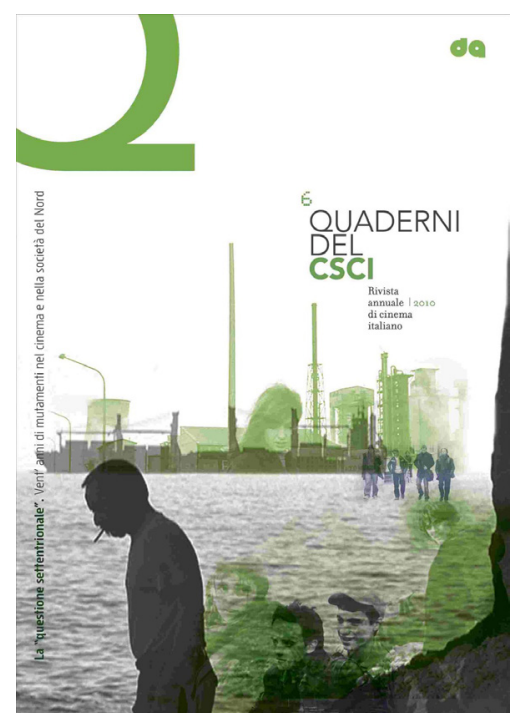

VV.AA., "La "questione settentrionale". Vent" anni di mutamenti nel cinema en ella società del Nord». Quaderni del CSCI. Revista annuale di cinema italiano, n. ${ }^{\circ}$ 6, 2010.
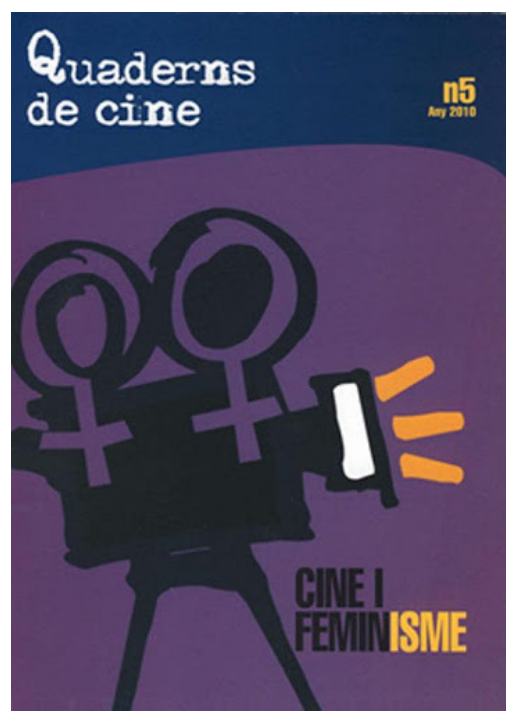

Quaderns de cine, n. ${ }^{\circ}$ 5, 2010.
[84] José Enrique Monterde (eds.), «Ficciones históricas» (Cuadernos de la Academia, n. $\left.{ }^{\circ} 6,1999\right)$.

[85] Carlos F. Heredero (ed.), «La imprenta dinámica. Literatura española en el cine español» (Cuadernos de la Academia, n. $\left.{ }^{\circ} 11-12,2001\right)$.

[86] Daniel Sánchez Salas y Bernardo Sánchez Salas (eds.), «Doce. Historia de la academia, 1986-1998» (Cuadernos de la Academia, n. $\left.{ }^{\circ} 4,1998\right)$.

[87] VV.AA., «Segni, disegni, sogni : l'universo di Federico Fellini» (Quaderni del CSCI, n. $\left.{ }^{\circ} 1,2005\right)$, pp. 12-156.

[88] VV.AA., «Il miraggio del reale: per una mappa del cinema documentario italiano» (Quaderni del CSCI, n. ${ }^{\circ}$ 4, 2008), pp. 12-178.

[89] VV.AA., «Le guerre nel cinema italiano dal 1911 a oggi» (Quaderni del CSCI, n. ${ }^{\circ} 12$, 2016), pp. 12-253.

[9o] Félix Monguillot Benzal, «Producciones cinematográficas hispano-italianas» (Quaderni del CSCI, n. ${ }^{\circ}$ 1, 2005), pp. 188-194.

[91] Daniela Aronica, «L'assedio dell'Alcazar/Sin novedad en el Alcázar (1940) de Augusto Genina. Análisis de la película restaurada» (Quaderni del CSCI, n. $\left.{ }^{\circ} 3,2007\right)$, pp. 164-174.

[92] Manuel González Casanova, «Presencia del cine italiano en el cine mudo mexicano» (Quaderni del CSCI, n. ${ }^{\circ}$, 2008), pp. 178-184. 
[93] VV.AA., «Cine i ensenyament» (Quaderns de Cine, n. ${ }^{\circ}$ 1, 2007).

[94] VV.AA., "Cine i memòria històrica» (Quaderns de Cine, n. $\left.{ }^{\circ} 3,2008\right)$.

[95] VV.AA., "Cine i feminisme» (Quaderns de Cine, n. ${ }^{\circ} 5$, 2010).

[96] VV.AA., "Cine y músicas populares urbanas» (Quaderns de Cine, . $^{\circ} 9,2014$ ).

[97] VV.AA., «Cine y videojuegos» (Quaderns de Cine, n. $^{\circ}$ 12, 2017).

[98] Pablo Puertas Carretero, «El nombre de la rosa (The Name of the Rose, Jean-Jacques Annaud, 1986)» (Metakinema, $n .^{0} 1,2007$ ).

[99] Francisco Javier Alonso Magaz, «Sierra de Teruel (L'espoir, André Malraux, 1939)» (Metakinema, n. ${ }^{\circ}$, 2008).

[10o] Isabel Sempere Serrano, «El Cid (Anthony Mann, 1961)» (Metakinema, n. ${ }^{\circ} 8,2011$ ).

[101] Antonio Aguilera Vita, «300 (Zack Snyder, 2007)» (Metakinema, $n .^{\circ}$ 1, 2007).

[102] Pablo Puertas Carretero, «Alatriste (Agustín Díaz Yanes, 2006)» (Metakinema, n. ${ }^{\circ} 4$ 2009).
Dos años más tarde, en 2007, aparecen Quaderns de Cine y Metakinema. La primera, dirigida por Juan Antonio Ríos Carratalá y editada por el Vicerrectorado de Extensión Universitaria de la Universitat d'Alacant. La revista se compone de textos analíticos e historiográficos dedicados al tratamiento de determinadas cuestiones en el cine. En el número 1 apunta como objetivo convertirse en un canal de difusión de trabajos de investigadores y docentes. Así, sus números tienen por títulos «Cine i ensenyament» ${ }^{93}$, «Cine i memòria històrica ${ }^{94}$, «Cine i feminisme» ${ }^{95}$, «Cine $\mathrm{y}$ músicas populares urbanas» ${ }^{96} \mathrm{O}$ «Cine $\mathrm{y}$ videojuegos» ${ }^{97}$.

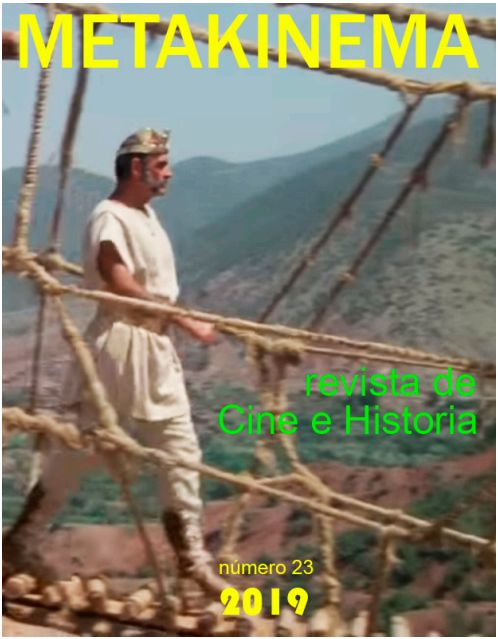

Metakinema. Revista de cine e historia, $\mathrm{n}^{\circ}$ 23, 2019.

Sus contenidos, intereses y vinculación académica sitúan a Metakinema cerca de Filmhistoria. La revista nace en la Universidad de Granada en 2007. Partiendo de la consideración de que toda película retrata la sociedad que la genera - sin por ello perder su especificidad-y en cierta medida actúa sobre ella, analiza títulos relevantes de la historia del cine y los estrenos recientes. Entre los primeros destacan las aproximaciones a El nombre de la rosa (The Name of the Rose, Jean-Jacques Annaud, 1986) ${ }^{98}$, Sierra de Teruel (L'Espoir, André Malraux, 1939) ${ }^{99}$ o El Cid (Anthony Mann, 1961) ${ }^{100}$; entre los estrenos recientes son importantes los análisis de 300 (Zack Snyder, 2007) ${ }^{101}$ o Alatriste (Agustín Díaz Yanes, 2006) ${ }^{102}$. La sección «A propósito de» aborda el tratamiento que ciertos personajes o hechos históricos han merecido en el cine. «Ensayo de transversalidad» $\mathrm{y}$ «Reflexión en torno a» tratan la obra de determinados cineastas y algunas películas que permiten una mirada social o cultural sobre la sociedad en la que viven, ciertas cinematografías emergentes, personajes clave de la historia del cine o aspectos como la conservación del patrimonio cinematográfico.

Con todo, si una revista destaca en estos momentos - y en la actualidades L'Atalante. Revista de Estudios Cinematográficos, hasta el punto de ser la única publicación dedicada al cine

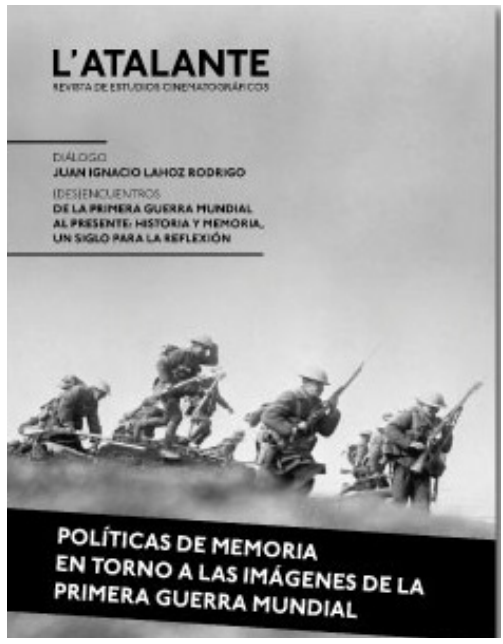

Àngel Quintana y Héctor Gómez Santa Olalla (coords.), «Políticas de memoria en torno a las imágenes de la Primera Guerra Mundial». L'Atalante. Revista de estudios cinematográfi$\cos$, n. $^{\circ} 21,2016$ 
que ha alcanzado la categoría Q2 de Scimago Journal \& Country Rank en 2017. La revista nace en 2003 como un proyecto editorial del entonces llamado Cinefòrum Comunicació Audiovisual, hoy Cinefòrum L'Atalante, de la Universitat de València. El antecedente de este es el Aula de Cinema, surgida en 1985 y coordinada por Vicente Benet, Mar Busquets Mataix, Amparo Gamir, José Antonio Hurtado y Francesc Picó, que desarrolla sus actividades de manera intermitente hasta 1996 y publica las revistas Butlletí de l'Aula de Cinema e Imatge. Como estas, L'Atalante surge como publicación de cariz cineclubista y universitario que persigue ampliar la labor divulgativa y crítica del cinefórum.

Sus contenidos se caracterizan en un primer momento por el afán divulgativo, a partir de extensos reportajes y artículos desvinculados de la actualidad cinematográfica. Desde el número 8 (2009), la revista tiene una periodicidad regular - semestral-, amplía su número de páginas y se dota de las secciones fijas «Cuaderno», «Diálogo», «(Des) encuentros» y «Puntos de fuga». La primera son dosieres de carácter monográfico dedicados al cine de animación español ${ }^{103}$, las teleseries norteamericanas contemporáneas ${ }^{104}$, la música rock y el cine ${ }^{105}$, el cómic y el cine ${ }^{106}$ o el cine español de los años cuarenta y cincuen$\mathrm{ta}^{107}$. Estos dosieres vienen acompañados de entrevistas a cineastas relacionados con las cuestiones que aborda en la sección «Diálogo». Igualmente relevante es «(Des)encuentros», sección que recoge el diálogo entre reconocidos especialistas y miembros de la redacción sobre diversos temas como los cines del sur ${ }^{108}$ o la relación entre cine e historia ${ }^{109}$. Con el tiempo también «(Des)encuentros» se vincula a «Cuaderno». Es el caso de «De la Primera Guerra Mundial al presente: historia y memoria, un siglo para la reflexión» ${ }^{110}$ en relación con el cuaderno «Políticas de memoria en torno a las imágenes de la Primera Guerra Mundial» ${ }^{111}$, entre otros. Finalmente, «Puntos de fuga», de carácter misceláneo, contiene análisis de películas o de determinados aspectos del cine.

A partir del número 21 (2016) L'Atalante se publica solo en su versión digital en internet. Este es un camino que han seguido todas las revistas académicas en los últimos años - en muchos casos conviviendo algunos números con la edición en papel-y, entre ellas, las dedicadas al cine. La reducción de los costes de producción, la posibilidad de ampliar su difusión -aunque sus lectores siempre estén acotados al mundo académico- y el hecho de que diversos criterios para baremar los méritos académicos primen la presencia en internet, han sido argumentos inapelables.

Entre las últimas publicaciones académicas dedicadas al cine destacan $\mathrm{FO}_{\mathrm{O}}$ tocinema. Revista Científica de Cine y Fotografía, dedicada como su nombre indica al cine y a la fotografía y editada por la Universidad de Málaga desde 2010 - recientemente ha aparecido en la misma universidad Trasvases entre la literatura y el cine-, Con A de Animación, publicada desde 2011 por la Universitat Politècnica de València, o Comparative Cinema, editada desde 2012 por el Colectivo de Investigación Estética de los Medios Audiovisuales (CINEMA) de la Universitat Pompeu Fabra y que analiza el cine desde una perspectiva comparatista. A estas podríamos añadir Área Abierta. Revista de Comunicación
[103] Noelia Pardo Mateu y Luis Pérez Ochando (coords.), «Animación española. Entusiasmo, exilio y resistencia» (L'Atalante. Revista de Estudios Cinematográficos, n. ${ }^{\circ}{ }_{10}$, 2010), pp. 5-47.

[104] Iván Bort Gual y Marta Martín Nuñez (coords.), «Las nuevas reglas del juego. Series de televisión dramáticas norteamericanas contemporáneas» (L'Atalante, n. $\left.{ }^{\circ} 11,2011\right)$, pp. 5-59

[105] Manuel de la Fuente y Marta Martín Nuñez (coords.), «Rock y cine. La música popular como discurso fílmico» (L'Atalante, n. ${ }^{\circ}$ 14, 2012), pp. 7-73.

[106] Diego Mollá y Jordi Revert (coords.), «Veinticuatro viñetas por segundo. Trasvases entre cine y cómic» (L'Atalante, n. $\left.{ }^{\circ} 16,2013\right)$, pp. 7-49

[107] José Luis Castro de Paz y Santiago Barrachina Asensio (coords.), «Heridas, pervivencias, transformaciones. Modelos de estilización en el cine posbélico español (1939-1962)» (L'Atalante, n. ${ }^{\circ}$ 20, 2015), pp. 7-64.

[108] VV.AA. "Viaje a los cines del sur» (L'Atalante, n. ${ }^{\circ}$ 9, 2010), pp. 56-67

[109] VV.AA. "Historia (et) Cinema» (L'Atalante, n. ${ }^{\circ}$ 10, 2010), pp. 57-67.

[110] VV.AA. «De la Primera Guerra Mundial al presente: historia y memoria, un siglo para la reflexión» (L'Atalante, n. $\left.{ }^{\circ} 21,2016\right)$, pp. 133-163.

[111] Àngel Quintana y Héctor Gómez Santa Olalla (coords.), «Políticas de memoria en torno a las imágenes de la Primera Guerra Mundial» (L'Atalante, n. $\left.{ }^{0} 21,2016\right), 19-120$. 


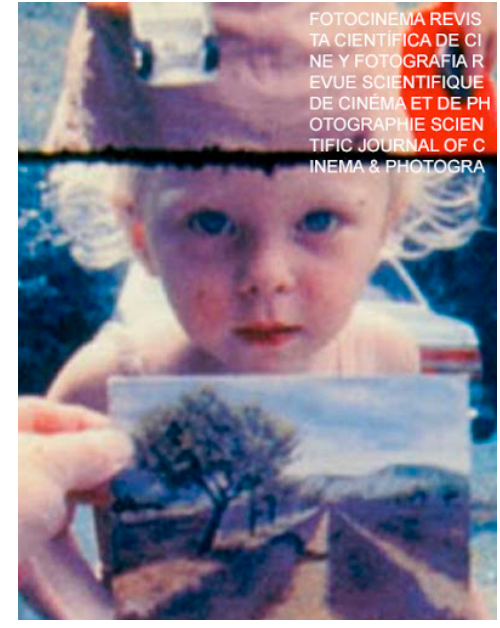

Fotocinema. Revista científica de cine y fotografía, n. ${ }^{\circ} 20,2020$.

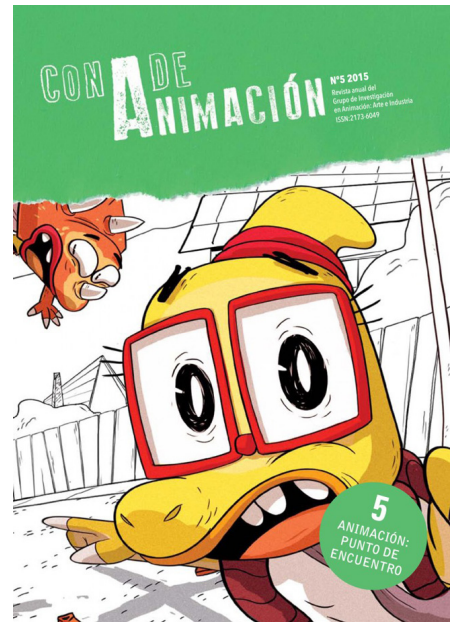

Con A de Animación, n. ${ }^{\circ}$ 5, 2015.

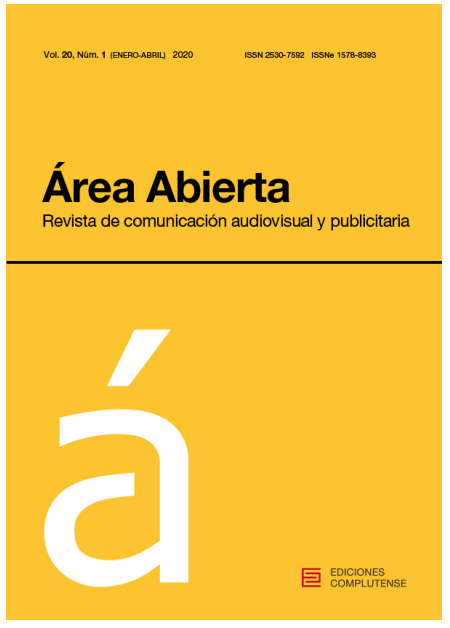

Área Abierta. Revista de Comunicación Audiovisual y Publicitaria, vol. 20, n. ${ }^{\circ}$ 2020.
[112] VV.AA., "Discurso y representación» (Eutopías. Documentos de trabajo, época I, n. ${ }^{\circ}$, vol. 1-2, 1985).

[113] VV.AA., «Semiótica y discurso» (Eutopías, época I, n. ${ }^{\circ} 1$, vol. 3,1985 ).

[114] VV.AA., «Metodologías del análisis de la imagen» (Eutopías, época I, n. ${ }^{\circ}$, vol. 1 , 1986).
Audiovisual y Publicitaria, revista dedicada a la Comunicación Audiovisual en general, pero cuyos últimos números han ido derivando hacia el cine.

No podemos olvidar en este inventario dos publicaciones que, si bien no están dedicadas en exclusiva al cine, han publicado textos relevantes sobre la materia: Eutopías. Documentos de Trabajo y Trama \& Fondo. Lectura y Teoría del Texto. La primera aparece en 1985 en el marco del Instituto de Cine y Radio-Televisión de la Universitat de València, publicándose en dos etapas hasta 1999. Está cerca de los supuestos teóricos y analíticos de Contracampo en un primer momento, aunque amplía sus contenidos hacia la literatura y la cultura desde la perspectiva de la semiótica. Sus directores son Jenaro Talens y Santos Zunzunegui. Los tres números de su primera etapa son monográficos - «Discurso y representación» ${ }^{112}$, «Semiótica y discurso» ${ }^{113}$ y «Metodologías del análisis de la imagen ${ }^{114}-$, y entre sus colaboradores destacan en esta época Juan Miguel Company, Francesco Casetti, Tom Conley, Román Gubern, Jesús González Requena, Jean Louis Leutrat, Vicente Hernández Esteve (Pau Esteve), Vicente Sánchez-Biosca o Santos Zunzunegui.

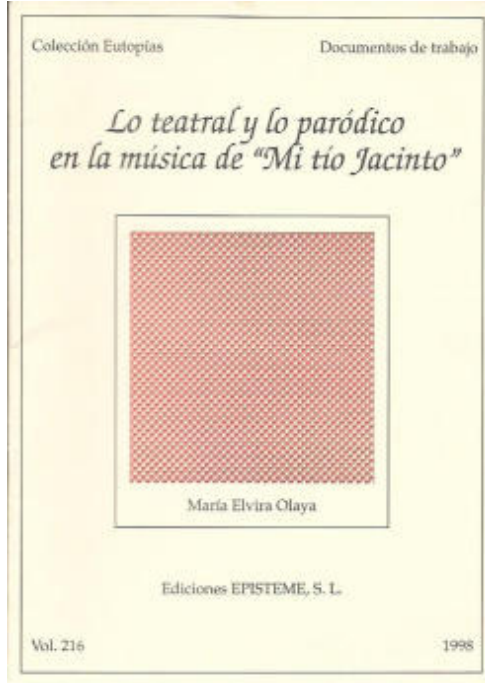

Maria Elvira Olaya, "Lo teatral y lo paródico en la música de "Mi tío Jacinto" ". Eutopías. Documentos de trabajo, n. ${ }^{\circ} 216,1998$. 
A partir de 1988 pasa a estar publicada por Ediciones Episteme, el Departament de Teoria dels Llenguatges, el Departament de Filosofia, el Departament d'Història Contemporània (Universitat de València), el Departamento de Lingüística General y Teoría de la Literatura (Universidad de Granada), el Instituto Miguel de Unamuno de Humanidades y Comunicación (Universidad Carlos III de Madrid), la Asociación Andaluza de Semiótica y la Asociación Vasca de Semiótica. Eutopías se compone ahora de números monográficos firmados por uno o dos autores. En el ámbito del cine y la comunicación audiovisual, la publicación tiene un papel relevante en la divulgación de algunos textos fundamentales de la teoría del cine, como es el caso de «Placer visual y cine narrativo», de Laura Mulvey ${ }^{115}$, «Cinéma et histoire», de Jean Louis Leutrat ${ }^{116}$, «Negociaciones sobre historia del cine», de Gilles Deleuze ${ }^{117}$, o «El concepto de cine nacional. El sujeto fantasmal del imaginario de la Historia del cine», de Thomas Elsaesser ${ }^{118}$. También da salida a trabajos de investigadores como Giulia Colaizzi — «Womanizing Film. Dorothy Arzner's Dance, Girl, Dance» ${ }^{119}-$, Imanol Zumalde - «Paisajes del odio. El dispositivo espacial de Centauros del desierto» ${ }^{120}$-, Àngel Quintana - «Mediación y transparencia. Un método didáctico para la utopía televisiva de Roberto Rossellini» ${ }^{121}-$, José Luis Castro de Paz - «La forma televisiva de Alfred Hitchcock. Los años 50, la crisis de Hollywood y la televisión» ${ }^{122}$ - o Vicente Sánchez-Biosca - «Funcionarios de la violencia. La violencia y su imagen en los campos de exterminio nazis ${ }^{123}-$. Tras su desaparición como publicación periódica, renace reconvertida en la colección de libros «Otras Eutopías», de Biblioteca Nueva, y en parte también en la colección «Frónesis», de Cátedra/Publicacions de la Universitat de València, aunque esta vez no está dedicada al cine. De alguna manera, los mismos

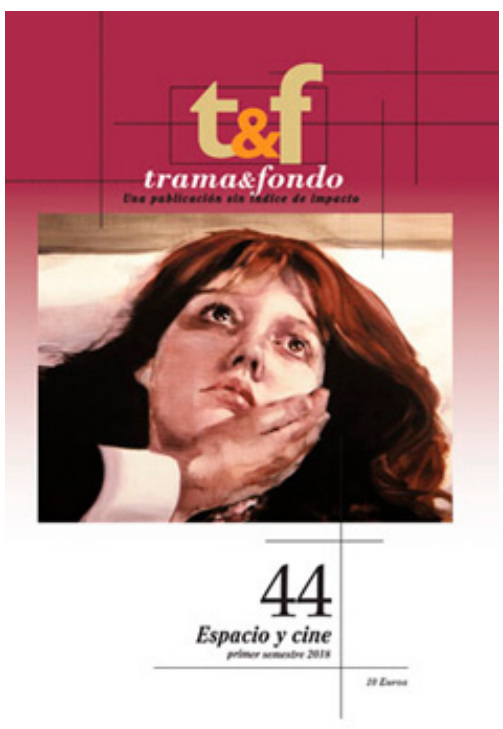

Trama \& Fondo, n. ${ }^{\circ} 44,2018$.
[115] Laura Mulvey, «Placer visual y cine narrativo» (Eutopías, época II, n. ${ }^{\circ} 1,1988$ )

[116] Jean Louis Leutrat, "Cinéma et histoire» (Eutopías, época II, n. $\left.{ }^{\circ} 72,1995\right)$.

[117] Gilles Deleuze, «Negociaciones sobre historia del cine» (Eutopías, época II, n. ${ }^{\circ} 111$, 1996).

[118] Thomas Elsaesser, «El concepto de cine nacional. El sujeto fantasmal del imaginario de la Historia del cine» (Eutopías, época II, n. $\left.{ }^{0} 166,1997\right)$.

[119] Giulia Colaizzi, «Womanizing Film. Dorothy Arzner's Dance, Girl, Dance» (Eutopías, época II, n. $\left.{ }^{\circ} 12,1992\right)$.

[120] Imanol Zumalde, «Paisajes del odio. El dispositivo espacial de Centauros del desierto" (Eutopías, época II, n. ${ }^{\circ}$ 84, 1995).

[121] Àngel Quintana, «Mediación y transparencia. Un método didáctico para la utopía televisiva de Roberto Rossellini» (Eutopías, época II, n. ${ }^{\circ} 134$, 1996). intereses y objetivos de Eutopías en lo que respecta al cine y el audiovisual fueron los que inspiraron la colección «Signo e Imagen» de Cátedra, en la que los creadores de la revista tuvieron un papel importante $\mathrm{e}^{124}$.

Trama \& Fondo. Lectura y teoría del texto ocupa un espacio editorial similar a Eutopías. Editada por la Asociación Cultural Trama y Fondo, aparece en 1996 dedicada al análisis cultural, con una presencia muy importante del cine y los medios audiovisuales. El hecho fílmico es abordado desde el psicoanálisis, la semiótica o la antropología. Tras unas primeras entregas de carácter misceláneo, sus contenidos se componen a modo de monográficos, entre los que destacan «Cine y psicoa-
[122] José Luis Castro de Paz, «La forma televisiva de Alfred Hitchcock. Los años 5o, la crisis de Hollywood y la televisión» 1997).

[123] Vicente Sánchez-Biosca, «Funcionarios de la violencia. La violencia y su imagen en los campos de exterminio nazis» (Eutopías, época II, n. ${ }^{\circ} 183$, 1997).

[124] Jenaro Talens, Juan Miguel Company «Estudis sobre el cinema: Valencia Film Publishing, Inc.», en Josep Luís Gómez I Mompart (ed.), «La recerca en comunicació en el País Valencià» (Treballs de Comunicació, $\mathrm{n}$. 22), pp. 161-170; y Jorge Nieto Ferrando y José Enrique Monterde, La prensa cinematográfica en España, 1910-2010 (Santander, Shangrila, 2018). (Eutopías, época II, n. ${ }^{\circ} 170$, 
[125] VV.AA., «Cine y psicoanálisis» (Trama \& Fondo. Lectura y teoría del texto, n. ${ }^{\circ}$ 7, 1999).

[126] VV.AA., "Cine y vanguardias» (Trama \& Fondo, n. ${ }^{\circ}$ 11, 2001).

[127] VV.AA., «Teatro, cine y psicosis» (Trama \& Fondo, n. ${ }^{\circ}$ 14, 2003).

[128] VV.AA., «El Holocausto» (Trama \& Fondo, n. ${ }^{\circ}$ 21, 2006).

[129] VV.AA., «Tramas de la verdad» (Trama \& Fondo, n. ${ }^{\circ}$ 24, 2008).

[130] Tampoco hay que llevarse a engaño, el número de investigaciones españolas sobre cine en las revistas de impacto -sean estas o no de cine- es meramente testimonial. Véase Aarón Rodríguez Serrano, José Antonio Palao Errando, Javier Marzal Felici, «Los estudios fílmicos en el contexto de las ciencias sociales: un análisis de autores, objetos y metodologías en las revistas de impacto españolas (2011-2017)» (BiD: Textos Universitarios de Biblioteconomía y Documentación, n. ${ }^{\circ}$ $43,2019)$ nálisis» ${ }^{125}$, «Cine y vanguardias» ${ }^{126}$, «Teatro, cine y psicosis» ${ }^{127}$, «El Holocausto» ${ }^{128} \mathrm{o}$ «Tramas de la verdad» ${ }^{129}$. En la actualidad (2020) su comité científico está formado por Adolfo Berenstein, Paolo Bertetto, Annie Busiere, José Luis Castro de Paz, Edmond Cros, Jesús González Requena, Gastón Lillo, Luis Martín Arias, Jenaro Talens, Jorge Urrutia y Santos Zunzunegui. Por sus páginas han aparecido las firmas de Jesús Bermejo, Lucio Blanco, Basilio Casanova, Miguel Ángel Lomillos, Víctor Lope, Luisa Moreno, Pilar Pedraza, Begoña Siles, Salvador Torres o Manuel Vidal Estévez.

\section{Consideraciones finales sobre la difusión de los trabajos acadé- micos sobre cine}

Hay una singular paradoja en el ámbito de las revistas académicas sobre cine. Ningún medio de comunicación cuenta con tantas publicaciones científicas prestándole atención - es difícil encontrar revistas dedicadas exclusivamente a la radio, a la televisión o a internet- $y$, sin embargo, su «valor académico» es limitado. En el sistema actual, publicar en las revistas aquí mencionadas ayuda poco a los investigadores a avanzar en su carrera académica y, por tanto, esta queda más todavía en manos de la buena voluntad de los evaluadores de sexenios, acreditaciones o proyectos de investigación. Es decir, ninguna de las revistas mencionadas ocupa el primer (Q1) o segundo cuartil (Q2) del Journal Citation Report y sus derivados o el primer cuartil de Scopus (SJR). La única que se acerca, como se ha comentado, es L'Atalante, una Q2 SJR, que en algunas evaluaciones puede tenerse en cuenta - en Cataluña, por ejemplo, no-.

Esto ha supuesto que muchos investigadores sobre cine busquen publicar en revistas internacionales -sobre hispanismo, por ejemplo, si se dedican al cine español- o en revistas bien valoradas en comunicación - Comunicar (Q1 JCR; Q1 SJR), Revista Latina de Comunicación Social (Q2 SJR) o Comunicación y Sociedad (Q2 SJR)-, en estudios literarios -Signa (Q1 SJR)-, en historia -Historia y Comunicación Social (Q1 SJR) - o en arte -Arte, Individuo y Sociedad (Q1 SJR)-. Obviamente, esto no es negativo, dado que pone en conexión al cine con otras disciplinas afines, lo que sin duda enriquece. Pero sí es trágico que, con la excepción de L'Atalante, ninguna de las revistas sobre cine haya alcanzado una valoración adecuada ${ }^{130}$.

Puede decirse que las publicaciones académicas dedicadas al cine se han encontrado en medio de la tormenta perfecta. En primer lugar, los cambios que introduce a principios del siglo XXI la Ley Orgánica de Universidades (6/2001) (LOU) determinan que la carrera académica de los profesores e investigadores españoles pase a depender, en buena medida, de las llamadas agencias de evaluación y acreditación. Si bien el objetivo era mitigar que el acceso y el ascenso en la carrera académica dependiera de la arbitrariedad, de filias y fobias o de cualquier otro «criterio extraacadémico», lo cierto es que los méritos de investigación han comenzado a depender exclusivamente del peso que las agencias otorgan a los artículos que se publican en las revistas que figuran en las horqui- 
llas superiores de determinadas bases de datos internacionales. El sistema lo fía todo a la posición que ocupan las revistas dentro de los rankings, sin tener en cuenta la calidad de los artículos concretos.

Cualquier investigador sobre cine sabía, a principios del siglo XXI, que la vía más adecuada para dar a conocer los resultados de sus investigaciones era publicando en alguna de las revistas que gozaban de cierto reconocimiento entre los miembros de su comunidad científica - bastantes de las que hemos mencionado más arriba-. El prestigio se lo habían ganado publicando, año tras año, artículos rigurosos - firmados, en muchas ocasiones, por reputados investigadores de la especialidad- que ampliaban nuestro conocimiento sobre la historia, la teoría o el análisis fílmico. El hecho de que algunas de estas publicaciones sigan difundiendo textos de referencia, más allá de su peso académico, ha llevado a muchos investigadores a desarrollar una suerte de personalidad escindida, diferenciando claramente las revistas que leen con gusto de aquellas en las que publican con gusto.

Ahora bien, ċcómo medir la calidad más allá de la revista con el nuevo sistema? ¿Cómo «elevar» un artículo publicado en una Q3 o «devaluar» un artículo aparecido en una Q1? La cuestión se ha intentado solucionar con el número de citas, lo que presenta dos problemas. Por una parte, muchas veces solo son accesibles - al menos automáticamente- las citas en textos publicados en internet, lo que deja de lado la enorme producción académica sobre cine en libros monográficos y colectivos en papel -que también han quedado prácticamente devaluados, por motivos parecidos a los que comentamos y también diferentes, que ya abordaremos en otra ocasión-. A ello hay que añadir la limitada fiabilidad de buscadores como Google Scholar, que, inexplicablemente, dejan de lado algunas publicaciones bien visibles.

Por otra parte, la importancia del número de citas - que no es una cosa nueva - ha conducido a la picaresca, al mercadeo de la cita. De manera que, en algunos artículos sobre cine, aparecen citas que poco o nada tienen que ver con la investigación y la argumentación que contienen, pero que permiten devolver otras citas recibidas o conservar buenas relaciones con los citados; o al revés, referencias sin duda obligatorias no aparecen en algunos artículos para evitar que el «no citado» aumente su capital académico.

En segundo lugar, las propias publicaciones académicas sobre cine han demostrado escasa capacidad de adaptación a las nuevas normas del juego, ya sea por su limitado margen de maniobra o, las menos, por mantener posiciones numantinas insostenibles. La migración a la edición en internet ha sido tardía, y se ha olvidado que el esperanto académico es el inglés. Esto conlleva publicar exclusivamente en inglés o, quizá lo más sensato, hacer ediciones bilingües, en cualquiera de las lenguas del estado y en inglés. Solo nos consta que L'Atalante esté siguiendo este camino, que requiere recursos o cargar los gastos de traducciones y correcciones sobre los investigadores, algo que puede espantar a muchos si la revista no alcanza ni una Q2 SJR.

De hecho, la falta de recursos es el principal problema de las publicaciones académicas dedicadas al cine. Escalar posiciones en las bases de datos interna- 
[131] Aarón Rodríguez Serrano, José Antonio Palao Errando y Javier Marzal Felici, «Los estudios fílmicos en el contexto de las ciencias sociales: un análisis de autores, objetos y metodologías en las revistas de impacto españolas (2011-2017)» (BiD: Textos Universitarios de Biblioteconomía y Documentación, vol. 43, 2019). cionales es imposible sin personal, tiempo, ni dinero, y los equipos de redacción ya tienen bastante con conseguir evaluadores, que estos entreguen a tiempo sus informes y que los números salgan con cierta regularidad. Aquí surge otra gran paradoja del mundo académico en el que nos movemos, que afecta a la investigación sobre cine, pero también a los estudios de comunicación, a las ciencias sociales y a las humanidades en general: se exige a los investigadores artículos Q1 y Q2 JCR, pero sin poner los medios para lograr que las revistas propias puedan alcanzar estas categorías. De esta manera, sin proporcionarle medios propios, recae sobre las espaldas del investigador -o del trabajador, si se prefiere- la responsabilidad si no alcanza los estándares internacionales de producción académica. Seguramente disponer de revistas académicas propias bien posicionadas académicamente y, por tanto, suficientemente dotadas ayudaría bastante a aumentar el prestigio de nuestra producción académica.

Finalmente, los investigadores y las revistas comparten responsabilidades. Un vistazo a las publicaciones comentadas muestra que bastantes artículos carecen de objetivos claros, un conocimiento mínimo sobre el estado de la cuestión, una metodología o fundamentos teóricos apropiados, rigurosos y ajustados al objeto de análisis y son meramente descriptivos. Es indudable que la etapa descriptiva resulta necesaria cuando un campo de investigación está poco explorado - y no debería penalizarse en esos casos-, pero su sentido es discutible cuando la literatura sobre el mismo es abundante. Decimos que la responsabilidad es compartida por los investigadores, que eluden las diferentes tradiciones teóricas y metodológicas que pueden fundamentar sus trabajos, y por las revistas, que en ocasiones son poco rigurosas a la hora de aceptar textos en sus páginas.

Sin duda el panorama de las revistas académicas sobre cine es desolador, al que se añade la escasísima presencia de proyectos sobre cine entre los adjudicatarios de los distintos programas de I+D o la ausencia de redes de investigación ${ }^{131}$ (Rodríguez, 2019). Partiendo de que todavía consideramos el cine un objeto de investigación relevante, solo un aumento de la autoexigencia de los investigadores y de los responsables de las publicaciones permitiría incrementar el prestigio de las revistas, al menos en la parte que podemos controlar. Sería volver al pasado, dado que las primeras publicaciones académicas nacieron de la insatisfacción, de la percepción compartida de que el cine era abordado desde el impresionismo y sin método ni bagaje teórico. Respecto a la parte que no podemos controlar, la falta de recursos o la manera de evaluar los méritos académicos, solo queda la protesta - o la lucha, si se prefiere-.

\section{Fuentes}

Aranzubia, Asier, «Entrevista telefónica del autor a Pablo del Río» (Madrid, 19 de mayo de 2015).

Comunicación XXI (1972 - 1978)

Film guía (1974 - 1977) 


\section{La Mirada (1978)}

Contracampo (1979-1987)

Dirigido por (1972 - )

Archivos de la Filmoteca (1989-)

Cuadernos de Cine. Textos críticos-Modos de ver (1981 - 1987)

Banda Aparte. Revista de cine/Formas de Ver (1994 - 2001)

Cinematògraf (1983-2001)

Ikusgaiak. Cuadernos de Cinematografía (1985 - )

Filmhistoria (1991 - )

Cinema Rescat. Butlletí de Lássociació Catalana per a la Recerca i Recuperació del Patrimoni Cinematogràfic (1996 - 2007)

Secuencias. Revista de historia del Cine (1994 - )

Cuadernos de la Academia (1997 - 2005)

Latente. Revista de Historia y Estética del Audiovisual (2003 - )

Quaderni del CSCI (2005 - )

Quaderns de Cine (2007 - )

Metakinema (2007 - )

L'Atalante. Revista de Estudios Cinematográficos (2003 - )

Fotocinema. Revista Científica de Cine y Fotografía (2010 - )

Trasvases entre la literatura y el cine (2019 - )

Con A de Animación (2011 - )

Comparative Cinema (2012 - )

Área Abierta. Revista de Comunicación Audiovisual y Publicitaria (2001 - )

Eutopías. Documentos de Trabajo (1985 -1999)

Trama \& Fondo. Lectura y teoría del texto (1996 - )

Comunicar (1994 - )

Revista Latina de Comunicación Social (1998 - )

Comunicación y Sociedad (1987 - )

Signa (1992 - )

Historia y Comunicación Social (1996 - )

Arte, Individuo y Sociedad (1988 - )

\section{Referencias Hemerográficas}

Archivos de la Filmoteca

Benet, Vicente J. y SÁnchez-Biosca, Vicente (coords.) (Archivos de la Filmoteca, n. ${ }^{0}{ }_{18}$, 1994)

BERTHIER, Nancy (coord.), «Cine y revolución cubana. Luces y sombras» (Archivos de la Filmoteca, n. $\left.{ }^{\circ} 59,2008\right)$, pp. 6-219.

Elena, Alberto y Paranaguá, Paulo Antonio (coords.), «Mitologías latinoamericanas» (Archivos de la Filmoteca, n. ${ }^{\circ}$ 31, 1999).

LuKÁcs, Georg, «Reflexiones sobre una estética del cine» (Archivos de la Filmoteca, n. ${ }^{0}$ 37, 2001), pp. 134-140.

PANofsky, Erwin, «El estilo y el medio en la imagen cinematográfica» (Archivos de la Filmoteca, n. $\left.{ }^{\circ} 35,2000\right)$, pp. 158-177.

SÁnchez-Biosca, Vicente (coord.), «La imagen del Alcázar en la mitología franquista» (Archivos de la Filmoteca, n. ${ }^{\circ}$ 35, 2000), pp. 45-156.

SÁnchEZ-BioscA, Vicente (coord.), «Materiales para una iconografía de Francisco Franco» (Archivos de la Filmoteca, n. ${ }^{\circ}$ 42-43, 2002-2003). 
Vilches, Gloria F., «Carmen en Hollywood» (Archivos de la Filmoteca, n. ${ }^{0}$ 51, 2005), pp. 9-108.

VV. AA., «Propuestas para la escritura de una historia del cine español» (Archivos de la Filmoteca, n. ${ }^{\circ}$ 1, 1989), pp. 14-47.

-, «Lo siniestro, la fotografía, el cine» (Archivos de la Filmoteca, n. $\left.{ }^{\circ} 8,1990-1991\right)$, pp. 6-32.

-, «Itinerarios del cine primitivo americano (1895-1915)» (Archivos de la Filmoteca, n. ${ }^{\circ}$ 2, 1989), pp. 76-114.

-, «Una cita fuera de cuadro. Cine y pintura» (Archivos de la Filmoteca, n. ${ }^{\circ}$ 11, 1992), 48-109.

-, «Sierra de Teruel, cincuenta años de esperanza» (Archivos de la Filmoteca, n. ${ }^{\circ} 3$, 1989).

Banda Aparte

VV. AA., «Reencuadres: David Lynch-Tod Browning» (Banda Aparte, n. ${ }^{0}$ 11, 1998), pp. $15-52$.

-, «Reencuadres: Marc Recha» (Banda Aparte, n. ${ }^{0}$ 14-15, 1999), pp. 20-34.

-, «Reencuadres: Agnès Varda» (Banda Aparte, n. ${ }^{\circ}$ 19, 2000), pp. 19-46.

-, «Reencuadres: Cine iraní» (Banda Aparte, n. ${ }^{0} 16,1999$ ), pp.74-91.

-, «Reencuadres: La imagen pornográfica» (Banda Aparte, n. ${ }^{\circ}$ 19, 200o), pp. 47-75.

-, «Reencuadres: Cine y Clase Obrera» (Banda Aparte, n. ${ }^{0}$ 17, 2000), pp. 17-46.

Cinema Rescat. Butlletí de L'associació Catalana per a la Recerca i Recuperació del Patrimoni Cinematogràfic

VV. AA., «Especial Guerra Civil i cinema» (Cinema Rescat, $\mathrm{n}^{0}$ 5, 1998).

-, «75è aniversari del naixement del cinema amateur» (Cinema Rescat, n. ${ }^{\circ}$ 6, 1998), pp. 5-24.

-, «Especial cinema no professional - Cinema amateur» (Cinema Rescat, n. ${ }^{0}$ 7, 1999).

-, «Especial Segundo de Chomón» (Cinema Rescat, n. ${ }^{\circ}$ 9, 2000).

\section{Cinematògraf}

Aмоrós, A., «Els estudis cinematogràfics Orphea» (Cinematògraf, época I, n. ${ }^{\circ}$ 1, 19831984), pp. 69-102.

GonzÁlez, Palmira, «Studio Films. La productora més comercial del cinema mut a Catalunya (1915-1922)» (Cinematògraf, época I, n. ${ }^{\circ}$ 2, 1984-1985), pp. 111-131.

Minguet BATLlori, Joan M., «El noucentisme contra el cinematògraf (La campanya anticinematogràfica de la revista Cataluña)» (Cinematògraf, época I, n. ${ }^{\circ} 3,{ }^{1985}$ 1986), pp.21-68.

Ripoll-Freixes, Enric, ““Cercle Lumiere”, Cine-club de l'Institut Francès de Barcelona» (Cinematògraf, época I, n. ${ }^{\circ}$ 2, 1984-1985), p. 277-304.

Romaguera i Ramio, Joaquim, «Seixanta anys de la "Biblioteca del Cinema Delmiro de Caralt” (Cinematògraf, época I, n. ${ }^{0}$ 2, 1984-1985), pp. 199-232.

VV. AA.., «La historiografia cinematogràfica a Catalunya» (Cinematògraf, época II, n. ${ }^{\circ}$ 1, 1992).

-, «Infraestructures industrials» (Cinematògraf, época II, n. ${ }^{0} 2,1995$ ).

-, «El cinema espanyol, de l'adveniment i la implantació del cinema sonor (1929) a l'esclat de la guerra civil» (Cinematògraf, época II, n. ${ }^{\circ} 3,2001$ ). 


\section{Contracampo}

-, «El discurso televisivo» (Contracampo, n. ${ }^{\circ} 39,1985$ ).

-, «Enunciación y punto de vista» (Contracampo, n. ${ }^{\circ} 42,1987$ ).

Cuadernos de la Academia

CARnicero, Marisol y SÁnchez Salas, Daniel (eds.). «En torno a Buñuel» (Cuadernos de la Academia, n. ${ }^{\circ}$ 7-8, 2000).

Cerdán, Josetxo y Pérez Perucha, Julio. «Tras el sueño» (Cuadernos de la Academia, n. $\left.{ }^{\circ} 2,1998\right)$.

García de DueÑas, Jesús y Gorostiza, Jorge (eds.), «Los estudios cinematográficos españoles» (Cuadernos de la Academia, n. ${ }^{\circ}$ 10, 2001).

Gubern, Román (coord.), «Un siglo de cine en España» (Cuadernos de la Academia, n. ${ }^{\circ}$ 1, 1997).

Fernández Colorado, Luis y Couto Cantero, Pilar (coords.), «La herida de las sombras. el cine español en los años cuarenta» (Cuadernos de la Academia, n. ${ }^{\circ}$ 9, 2001).

Heredero, Carlos F. (ed.), «La imprenta dinámica. Literatura española en el cine español» (Cuadernos de la Academia, n. ${ }^{0}$ 11-12, 2001).

Lozano Aguilar, Arturo y Pérez Perucha, Julio (eds.), «El cine español durante la transición democrática (1974-1983)» (Cuadernos de la Academia, 13-14, 2005).

Monterde, José Enrique (eds.), «Ficciones históricas» (Cuadernos de la Academia, n. ${ }^{0}$ 6, 1999)

Sánchez Salas, Daniel y Sánchez Salas, Bernardo (eds.), «Doce. Historia de la academia, 1986-1998» (Cuadernos de la Academia, 4, 1998).

VV.AA., «Los límites de la frontera. La coproducción en el cine español», (Cuadernos de la Academia, n. ${ }^{0} 5$, 1999).

Eutopías. Documentos de trabajo

CASTRo de PAZ, José Luis, «La forma televisiva de Alfred Hitchcock. Los años 50, la crisis de Hollywood y la televisión» (Eutopías, época II, n. ${ }^{0}$ 170, 1997).

ColaIzzi, Giulia, «Womanizing Film. Dorothy Arzner's Dance, Girl, Dance» (Eutopías, época II, . $^{\circ} 12,1992$ ).

Deleuze, Gilles, «Negociaciones sobre historia del cine» (Eutopías, época II, n. ${ }^{0} 111$, 1996).

ELSAESSER, Thomas, «El concepto de cine nacional. El sujeto fantasmal del imaginario de la Historia del cine» (Eutopías, época II, n. ${ }^{\circ}$ 166, 1997).

LeUtrat, Jean Louis, «Cinéma et histoire» (Eutopías, época II, n. ${ }^{0} 72,1995$ )

Mulvey, Laura, «Placer visual y cine narrativo» (Eutopías, época II, n. ${ }^{\circ} 1,1988$ )

QuintANA, Àngel, «Mediación y transparencia. Un método didáctico para la utopía televisiva de Roberto Rossellini» (Eutopías, época II, n. ${ }^{0} 134,1996$ ).

SÁnchez-Biosca, Vicente, «Funcionarios de la violencia. La violencia y su imagen en los campos de exterminio nazis» (Eutopías, época II, n. ${ }^{0}$ 183, 1997).

-, «Discurso y representación» (Eutopías, época I, n. ${ }^{\circ}$ 1, vol. 1-2, 1985).

-, «Semiótica y discurso» (Eutopías, época I, ${ }^{0}$. 1, vol. 3, 1985).

-, «Metodologías del análisis de la imagen» (Eutopías, época I, n.2, vol.1, 1986).

Zumalde, Imanol, «Paisajes del odio. El dispositivo espacial de Centauros del desierto» (Eutopías, época II, n. ${ }^{\circ}$ 84, 1995). 
Ikusgaiak. Cuadernos de cinematografía

Ansola, Txomin, «Crisis y recuperación de la exhibición cinematográfica en Barakaldo (1980-1997) (Ikusgaiak, n. ${ }^{\circ}$ 4, 2000), pp. 151-164.

DíEz, Emeterio, «La política cinematográfica del primer gobierno de Euskadi: la gerencia de espectáculos púbicos (1936-1937)» (Ikusgaiak, n. ${ }^{\circ}$ 5, 2001) pp. 117-132.

Eтxевеste Gómez, Zigor, «Julio Medem, a través del espejo de la realidad» (Ikusgaiak, n. $\left.{ }^{\circ} 6,2003\right)$, pp. 117-134.

Gamarra Quintanilla, Garikoitz, «A propósito de Arrebato: Ascética y Cultura Pop» (Ikusgaiak, n. ${ }^{\circ} 5$, 2001), pp. 37-63.

Gutiérrez Márquez, Juan Miguel, «Sombras de la caverna. El tempo vasco en el cine» (Ikusgaiak,.$^{\circ}{ }^{2}$, 1997).

ItUARTe Pérez, Leire, «Breve inventario del imaginario posmoderno en El día de la Bestia: proyecciones utópicas de una distopia urbana» (Ikusgaiak, $\mathrm{n}^{0} 7,2004$ ), pp. 125-136.

Lomillos, Miguel Ángel, «La concepción y experiencia del cine en la obra de Víctor Erice» (Ikusgaiak, n. ${ }^{\circ}$ 6, 2003), pp. 37-60.

Roldán Larreta, Carlos, «El cine del País Vasco. De Amalur (1968) a Airbag (1997)» (Ikusgaiak, n. $\left.{ }^{\circ} 3,1999\right)$.

UnSaIN, José María, «El cine y los vascos» (Ikusgaiak. Cuadernos de Cinematografía, n. $\left.{ }^{0} 1,1985\right)$.

\section{Filmhistoria}

AlEgre, Sergio, «Re-lectura de La Grande Illusion (1937)» (Filmhistoria, n. ${ }^{\circ}$ I, vol. 1, 1991), pp. 25-34.

CRuSELLS, Magi, «Libertarias: la utopía durante la Guerra Civil española no fue solo cosa de hombres» (Filmhistoria, n. ${ }^{\circ}$ VI, vol. 3, 1996), pp. 295-300.

Cuevas, Efrén, «La sociedad estadounidense bajo la mirada de Elia Kazan» (Filmhistoria, n. ${ }^{0}$ VIII, vol. 1, 1998), pp. 29-49.

GonZÁlez, Fernando, «Basilio Martín Patino: pensar la Historia» (Filmhistoria, n. ${ }^{\circ}$ VII, vol. 2, 1997), pp. 141-16o.

\section{L'Atalante. Revista de estudios cinematográficos}

Bort Gual, Iván y Martín NúÑEz, Marta (coords.), «Las nuevas reglas del juego. Series de televisión dramáticas norteamericanas contemporáneas» (L'Atalante, . $^{\circ}$ 11, 2011), pp. 5-59.

Castro de Paz, José Luis y Barrachina Asensio, Santiago (coords.), «Heridas, pervivencias, transformaciones. Modelos de estilización en el cine posbélico español (19391962)» (L'Atalante, n. ${ }^{\circ}$ 20, 2015), pp. 7-64.

Fuente Soler, Manuel de la y MarTín Núñez, Marta (coords.), «Rock y cine. La música popular como discurso fílmico» (L'Atalante, n. ${ }^{\circ}$ 14, 2012), pp. 7-73.

Mollá, Diego y ReverT, Jordi (coords.), «Veinticuatro viñetas por segundo. Trasvases entre cine y cómic» (L'Atalante, n. ${ }^{\circ}$ 16, 2013), pp. 7-49.

Pardo Mateu, Noelia y Pérez Ochando, Luis (coords.), «Animación española. Entusiasmo, exilio y resistencia» (L'Atalante, $.^{\circ}{ }^{10}, 2010$ ), pp. 5-47.

Quintana, Àngel y Gómez Santa Olalla, Héctor (coords.), «Políticas de memoria en torno a las imágenes de la Primera Guerra Mundial» (L'Atalante, n. ${ }^{0}$ 21, 2016), 19-120.

VV.AA., «Historia (et) Cinema (L'Atalante, n. ${ }^{\circ}$ 10, 2010), pp. 57-67.

-, «Viaje a los cines del sur (L'Atalante, n. ${ }^{\circ}$ 9, 2010), pp. 56-67. 
-, «De la Primera Guerra Mundial al presente: historia y memoria, un siglo para la reflexión» (L'Atalante, n. ${ }^{\circ}$ 21, 2016), pp. 133-163.

\section{Metakinema}

Alfonso Magaz, Francisco Javier, «Sierra de Teruel (L'Espoir, André Malraux, 1939)» (Metakinema, n. ${ }^{0}$ 2, 2008).

Aguilera Vita, Antonio, «30o (Zack Snyder, 2007)» (Metakinema, n. ${ }^{\circ}$ 1, 2007).

Puertas CARretero, Pablo, «El nombre de la rosa (The Name of the Rose, Jean-Jacques Annaud, 1986)» (Metakinema, n. ${ }^{\circ}$ 1, 2007).

-, «Alatriste (Agustín Díaz Yanes, 2006)» (Metakinema, n. ${ }^{\circ} 4,2009$ ).

Sempere Serrano, Isabel, «El Cid (Anthony Mann, 1961)» (Metakinema, n.o 8, 2011).

\section{Quaderni del CSCI}

ARonicA, Daniela, «L'assedio dell'Alcazar/Sin novedad en el Alcázar (1940) de Augusto Genina. Análisis de la película restaurada» (Quaderni del CSCI, n. ${ }^{\circ} 3,2007$ ), pp. 164-174.

GonzÁlez Casanova, Manuel, «Presencia del cine italiano en el cine mudo mexicano» (Quaderni del CSCI, n. ${ }^{\circ}$ 4, 2008), pp. 178-184.

Monguilot Benzal, Félix, «Producciones cinematográficas hispano-italianas» (Quaderni del CSCI, n. ${ }^{\circ}$ 1, 2005), pp. 188-194.

VV.AA., «Segni, disegni, sogni : l'universo di Federico Fellini» (Quaderni del CSCI, n. ${ }^{\circ}$ 1, 2005), pp. 12-156.

-, «Il miraggio del reale: per una mappa del cinema documentario italiano» (Quaderni del CSCI, n. $\left.{ }^{\circ} 4,2008\right)$, pp. 12-178.

-, «Le guerre nel cinema italiano dal 1911 a oggi» (Quaderni del CSCI, n. ${ }^{\circ} 12,2016$ ), pp. 12-253.

Quaderns de Cine

VV.AA., "Cine i ensenyament» (Quaderns de Cine,.$^{\circ}{ }^{0}$ 1, 2007).

-, «Cine i memòria històrica» (Quaderns de Cine, $\mathrm{n}^{\circ}{ }^{0}$, 2008).

-, «Cine i feminisme» (Quaderns de Cine, $\left.n .{ }^{\circ} 5,2010\right)$.

-, «Cine y músicas populares urbanas» (Quaderns de Cine, n. ${ }^{\circ}$ 9, 2014).

—, «Cine y videojuegos» (Quaderns de Cine, n. ${ }^{0}$ 12, 2017).

Secuencias. Revista de Historia del Cine

Berthier, Nancy, «El último caído de Sáenz de Heredia, un poema documental sobre Franco» (Secuencias, n. ${ }^{\circ}$ 2, 1995), pp. 9-29.

CAmporesi, Valeria y Parrondo Copel, Eva (eds.), «Cine y mujer. (Re)visiones feministas» (Secuencias, n. $\left.^{\circ} 15,2002\right)$.

CAstro de Paz, José Luis, «David Bordwell, el "modo de práctica fílmica” y la reciente historiografía del cine en España» (Secuencias, n. ${ }^{0}$ 3, 1995), pp.111-114.

Díaz, Marina (ed.), «Cine y política en América Latina» (Secuencias, n. ${ }^{0} 10,1999$ ).

ELENA, Alberto, «¿Quién prohibió Rojo y negro?» (Secuencias, n. ${ }^{0}$ 7, 1997), pp. 63-78.

- (ed.), «Cine y migraciones. La experiencia hispanoamericana» (Secuencias, n. ${ }^{\circ}$ 22, 2005) 
Elena, Alberto y SAn Miguel, Helio (eds.), «El nuevo Bollywood» (Secuencias, n. ${ }^{\circ}$ 36, 2012)

López Rubio, Clara y Martin Hamdorf, Wolf, «Los archivos de la Unión Soviética. Entrevista a Naum Kleiman» (Secuencias, n. ${ }^{\circ}$ 2, 1995), pp. 81-94.

Muñoz Aunión, Marta, «El cine español según Goebbels. Apuntes sobre la versión alemana de Carmen la de Triana» (Secuencias, n. ${ }^{0}$ 20, 2004), pp. 25-46.

Trama \& Fondo. Lectura y Teoría del Texto

VV.AA., «Cine y psicoanálisis» (Trama \& Fondo, n. $\left.{ }^{\circ} 7,1999\right)$

-, «Cine y vanguardias» (Trama \& Fondo, $\mathrm{n} .{ }^{0} 11,2001$ ).

-, «Teatro, cine y psicosis» (Trama \& Fondo, n. ${ }^{\circ}$ 14, 2003).

-, «El Holocausto» (Trama \& Fondo, n. ${ }^{0}$ 21, 2006).

-, «Tramas de la verdad» (Trama \& Fondo, n. ${ }^{\circ}$ 24, 2008).

\section{Bibliografía}

Aranzubia, Asier, «Vida y milagros de una revista de combate. Contracampo (19791987)», en Jenaro Talens y Santos Zunzunegui (eds.), Contracampo. Ensayos sobre teoría e historia del cine (Madrid, Cátedra, 2007), pp. 13-34.

-, Los mecanismos comunicativos del cine de todos los días. Antología del colectivo Marta Hernández y Javier Maqua en Comunicación XXI (Santander, Shangrila, 2016).

Aranzubia, Asier y Nieto Ferrando, Jorge, «Un idilio efímero o de cómo el influjo de la teoría renovó la crítica cinematográfica española en los años 70» (Secuencias. Revista de historia del cine, n. $\left.^{\circ} 37,2013\right)$, pp. 62-82.

CAPARrós Lera, José María (coord.), Cine español. Una historia por autonomías (Vol. Iy II) (Barcelona, Promociones y publicaciones universitarias, 1996).

Montiel, Alejandro. «Días inolvidables. La recepción del cine español de la transición en los editoriales de contracampo», en Arturo Lozano Aguilar y Julio Pérez Perucha (eds.), «El cine español durante la transición democrática (1974-1983)» (Cuadernos de la Academia, 13-14, 2005), pp. 257-274.

Nieto Ferrando, Jorge, Cine en papel. Cultura y crítica cinematográfica en España (1962-1982) (Valencia, Ediciones de la Filmoteca, 2012).

-, «Libros y revistas de cine», en Jorge Nieto Ferrando y Agustín Rubio Alcover (eds.), Diccionario del audiovisual valenciano (Valencia, Ediciones de la Filmoteca), pp. 493-500.

-, «La prensa cinematográfica española como fuente y objeto de la historia del cine. Análisis y evolución de sus contenidos (1910-2010)» (Historia y Comunicación Social, n. ${ }^{0}$ 24, vol. 11, 2019), pp. 237-258. DOI: https://doi.org/10.5209/hics.64493

Nieto Ferrando, Jorge y Monterde, José Enrique, La prensa cinematográfica en España, 1910-2010. (Santander, Shangrila, 2018).

Peláez Paz, Andrés (1998). «Las publicaciones», en Daniel Sánchez Salas y Bernardo Sánchez Salas (coords.), «Doce. Historia de la academia, 1986-1998» (Cuadernos de la Academia, 4, 1998), 91-112. 
Rodríguez Serrano, Aarón, Palao Errando, José Antonio y Marzal Felici, Javier, «Los estudios fílmicos en el contexto de las ciencias sociales: un análisis de autores, objetos y metodologías en las revistas de impacto españolas (2011-2017)» (BiD: Textos Universitarios de Biblioteconomía y Documentación, vol. 43, 2019). DOI: https:// dx.doi.org/10.1344/BiD2019.43.7

Rodrigo García, Jesús, «Ediciones de la Mirada», (Métodos de Información, n. ${ }^{0}$ 7, 2000), pp. 38-39.

SÁNchez BARBA, Francesc, Brumas del franquismo. El auge del cine negro español (19501965) (Barcelona, Universitat de Barcelona, 2007).

Talens, Jenaro y Company, Juan Miguel (2007). «Estudis sobre el cinema: Valencia Film Publishing, Inc.», en Josep Luís Gómez Mompart (ed.), «La recerca en comunicació en el País Valencià» (Treballs de Comunicació, 22), pp. 161-170.

Zumalde, Imanol, La experiencia filmica. Cine, pensamiento y emoción (Madrid, Cátedra, 2011). 